\title{
Review Article Neuroprotection in Glaucoma: Old and New
Promising Treatments
}

\author{
Dario Rusciano, ${ }^{1}$ Salvatore Pezzino, ${ }^{2}$ Maria Giulia Mutolo, ${ }^{3}$ Rossella Giannotti, ${ }^{4}$ \\ Aloisa Librando, ${ }^{4}$ and Nicola Pescosolido ${ }^{5}$ \\ ${ }^{1}$ Sooft Italia S.p.A., Via Salvatore Quasimodo 136, Rome, Italy \\ ${ }^{2}$ Bioos Italia S.r.l., Viale Andrea Doria 21, Catania, Italy \\ ${ }^{3}$ Ophthalmology Clinic of the Sant'Andrea Hospital of Rome, Sapienza University of Rome, Rome, Italy \\ ${ }^{4}$ Department of Sense Organs, Sapienza University of Rome, Rome, Italy \\ ${ }^{5}$ Department of Cardiovascular, Respiratory, Nephrology, Anesthesiology and Geriatric Sciences, \\ Sapienza University of Rome, Rome, Italy \\ Correspondence should be addressed to Dario Rusciano; dario.rusciano@sooft.it
}

Received 21 April 2017; Revised 2 September 2017; Accepted 13 September 2017; Published 17 October 2017

Academic Editor: Antonio Ferrer-Montiel

Copyright (C) 2017 Dario Rusciano et al. This is an open access article distributed under the Creative Commons Attribution License, which permits unrestricted use, distribution, and reproduction in any medium, provided the original work is properly cited.

Glaucoma is a major global cause of blindness, but the molecular mechanisms responsible for the neurodegenerative damage are not clear. Undoubtedly, the high intraocular pressure (IOP) and the secondary ischemic and mechanical damage of the optic nerve have a crucial role in retinal ganglion cell (RGC) death. Several studies specifically analyzed the events that lead to nerve fiber layer thinning, showing the importance of both intra- and extracellular factors. In parallel, many neuroprotective substances have been tested for their efficacy and safety in hindering the negative effects that lead to RGC death. New formulations of these compounds, also suitable for chronic oral administration, are likely to be used in clinical practice in the future along with conventional therapies, in order to control the progression of the visual impairment due to primary open-angle glaucoma (POAG). This review illustrates some of these old and new promising agents for the adjuvant treatment of POAG, with particular emphasis on forskolin and melatonin.

\section{Introduction}

Glaucoma is a worldwide leading cause of irreversible blindness. It is a multifactorial optic neuropathy characterized by the progressive loss of retinal ganglion cells (RGCs) and their axons [1].

Although the etiopathogenesis of glaucoma is not fully understood, high intraocular pressure (IOP) appears to be related to RGC death, both in the case of acute closedangle glaucoma, when there is a sudden increase of IOP, and in the case of primary open-angle glaucoma (POAG), which develops relatively slowly over the years. POAG can be hypertensive (IOP $>21 \mathrm{mmHg}$ ) or normotensive (NTG: IOP $<21 \mathrm{mmHg}$ ). In either case, medical or surgical lowering of the IOP appears to delay the disease's progression $[2,3]$.

In glaucomatous patients, the increased resistance to aqueous drainage through the trabecular meshwork (POAG) and the obstruction of the drainage pathway by the iris (primary closed-angle glaucoma) are the main causes of IOP elevation $[4,5]$. Furthermore, several risk factors have been associated with glaucoma pathogenesis: older age, black race, Hispanic origin, family history of glaucoma, myopia, diabetes mellitus, and use of systemic or topical corticosteroids $[6,7]$.

Therefore, with POAG being a complex multifactorial disease, several events converge to induce RGC loss, such as IOP elevation, ischemia/reperfusion damage, oxidative/nitrosative stress, neurotrophic growth factor deprivation, activation of autoimmunity, and glutamate neurotoxicity (Figure 1(a)).

The growing knowledge of this disease and its etiopathogenesis has prompted the study of new targets and therapeutic agents aimed at stopping or delaying RGC neurodegeneration (Figure 1(b)). The goal of the present review is to discuss some of the old and promising new agents that may contribute to a better treatment of POAG. 


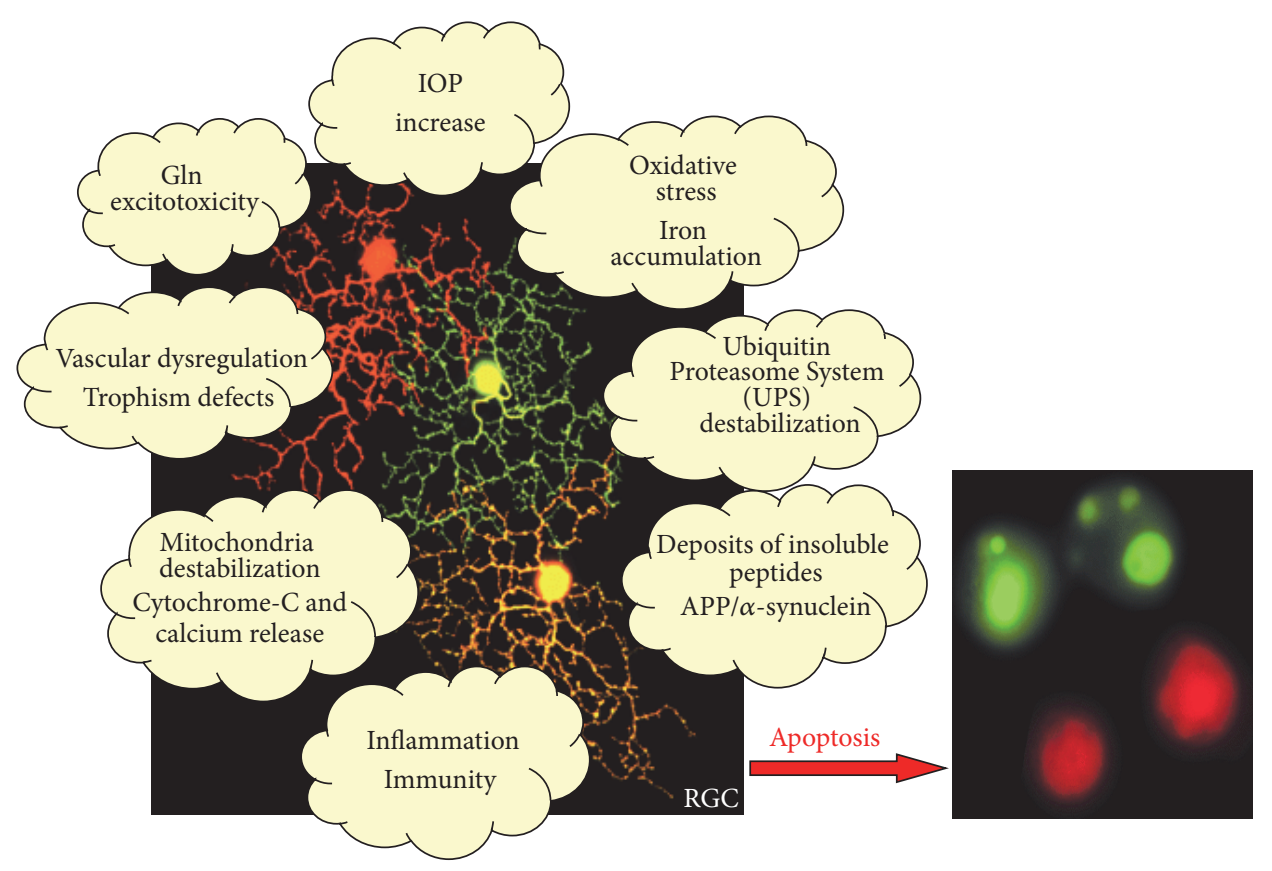

(a)

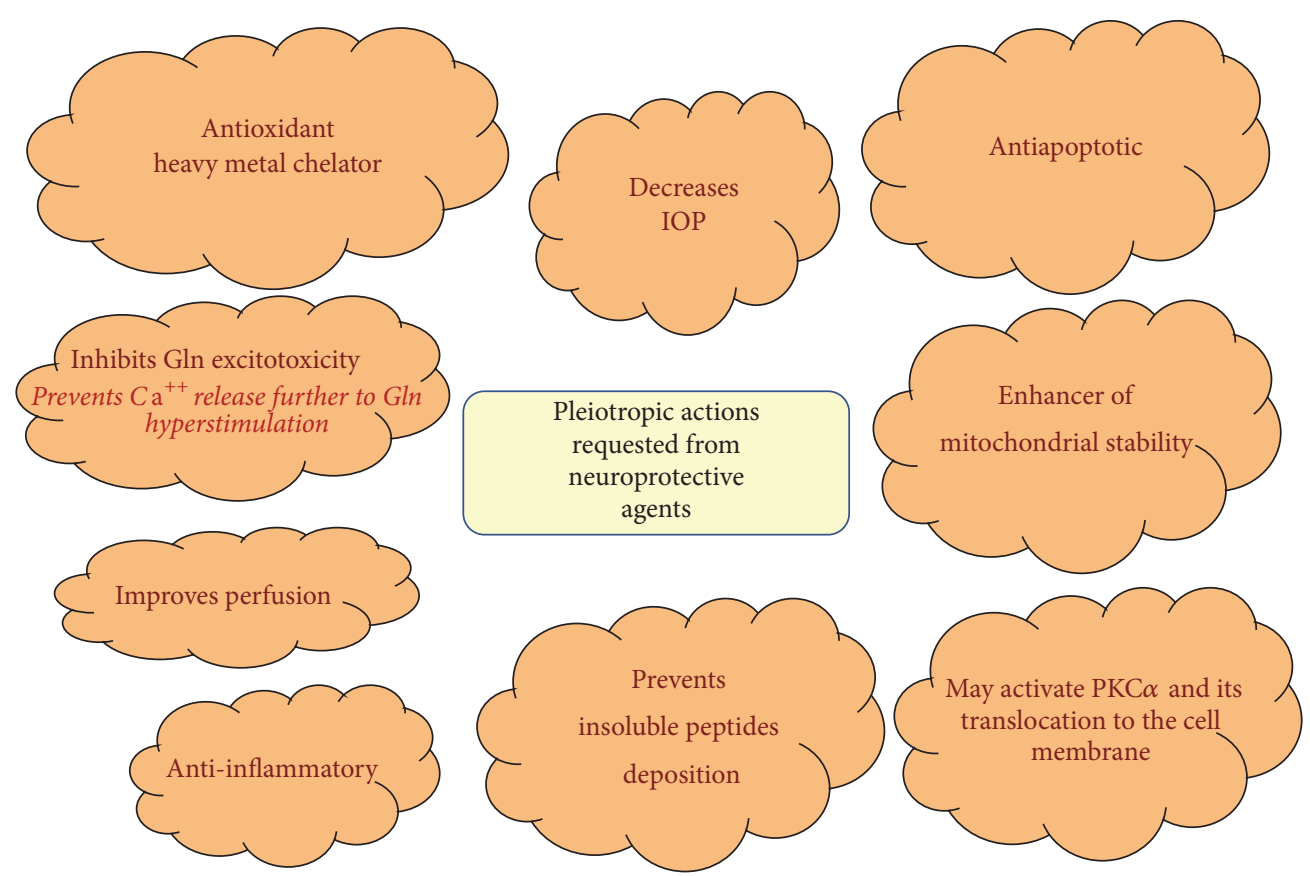

(b)

Figure 1: (a) Several different factors may contribute to the development and progression of POAG, finally triggering cell death, usually by apoptosis, of RGC. These factors could be considered potential targets of neuroprotective agents. (b) Due to the multifactorial nature of POAG, pleiotropic effects are expected from neuroprotective agents in order to achieve efficient neuroprotection.

\section{RGC Death and Neuroprotection Targets}

POAG presents with a typical progressive visual field loss and optic disk cupping due to the massive death of RGCs and their nerve fibers (usually more than $50 \%$ of RGCs are dead when the first visual field abnormalities are detectable) [8].

The major risk factors linked to the starting of the chain of events finally leading to overt POAG may be of genetic, mechanical, biochemical, or hemorheological nature. None of them by itself can explain or predict the insurgence and progression of the disease, which is most likely controlled by a combination of different factors, some of which probably still need to be identified.

A certain degree of familiarity exists for POAG, which has led to the discovery of several genes that may be associated 


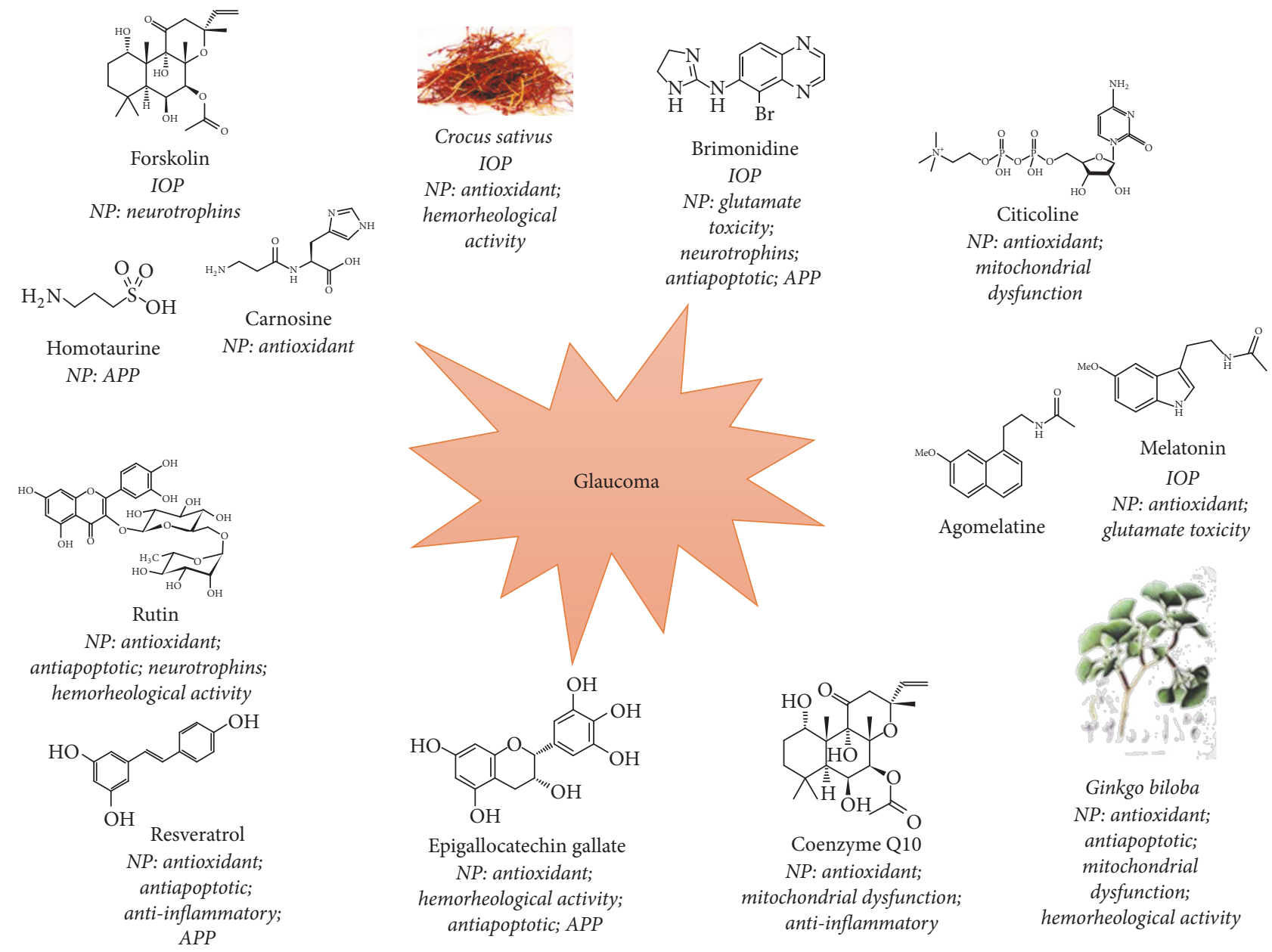

FIGURE 2: Schematic rendering of neuroprotective agents described in this review, summarizing their neuroprotective activities: no single molecule is endowed with all the required activities; brimonidine shows the highest number (5). IOP: hypotonizing effects; NP: neuroprotection mechanisms; APP (amyloid plaque protein): decrease of APP pathologic processing.

with the disease [9]; however, no single gene by itself has been found to cause POAG.

IOP increase is the main mechanical risk factor, which may stress both retinal layers and the lamina cribrosa through which RGC nerve fibers leave the eye, forming the optic nerve. This may result in ischemic injury, glial cell activation, reduced axoplasm flow, and neurotrophin deprivation, finally causing RGC apoptosis [10]. Further glutamate release from dying cells may cause an excitotoxic response in neighboring RGCs, triggering their apoptotic death in a vicious circle [11].

Oxidative stress induced by oxygen and nitrogen reactive species is also implicated in the etiology of POAG and several other eye disorders [12-15]. Several mechanisms involving antioxidant enzymes such as superoxide dismutase (SOD), as well as antioxidants such as glutathione and ascorbate, protect the eye from oxidative stress [16]. It has been found that POAG patients exhibit low levels of circulating glutathione, suggesting a general impairment of the antioxidative defense [17], while reduced expression of the antioxidant enzymes SOD and glutathione S-transferases was found in the aqueous humor of POAG patients, suggesting that this state could aggravate the balance between both oxygen- and nitrogenderived free radical production and their detoxification.

Defective blood perfusion of the retina and the optic nerve head may also be critical factors in POAG development and progression, with more relevance in the case of NTG [18].

Despite the identification of several risk factors for POAG, the main-if not the only-therapeutic target to treat glaucoma still remains the IOP. Even though clinical studies have shown that decreasing the IOP is necessary, it is not the only condition capable of preventing glaucoma development or progression [4]. Therefore, neuroprotection strategies have been developed in recent years, not to replace but to complement the classical IOP lowering approach [19], aiming at slowing down POAG progression. Several targets have been proposed for neuroprotection, and molecules acting on such targets can be classified as oligopotent or multipotent, depending on whether they may act on multiple targets or not. We have chosen here a selection of molecules belonging to either class, mostly based on our direct experience with them (Figure 2). 


\section{Forskolin}

Forskolin is a diterpene isolated from the root extract of Coleus forskohlii species [20]. It is a receptor-independent activator of adenylate cyclase. In forskolin-treated cells, the intracellular concentration of the second messenger cAMP is rapidly increased [21]. The adenylate cyclase complex is present both in ciliary body epithelial cells [22], deputed at producing the aqueous humor $(\mathrm{AH})$, and in trabecular meshwork (TM) cells, regulating the aqueous humor outflow [23]. Numerous studies have shown that forskolin is able to reduce IOP in animals and humans [24-32]. This happens probably because cAMP elevation in the ciliary body may lead to the activation of the chloride maxi channel in pigmented epithelial cells, facing the stroma, thus leading to resorption of $\mathrm{AH}$ from the posterior chamber into the stroma (Figure 3(a)) [33]. Conversely, alpha-agonists and beta-blockers decrease cAMP production in nonpigmented epithelial cells, thus decreasing the activity of the chloride channels facing the posterior chamber, leading to decreased AH secretion (Figure 3(a)) [34]. Moreover, cAMP elevation in TM cells might trigger the disassembly of the actin cytoskeleton through PKA activation and Rho kinase inhibition [35], thus increasing the TM outflow (Figure 3(b)) [36]. Therefore, forskolin treatment results in a reduced amount of $\mathrm{AH}$ accumulation in the anterior chamber (decreased secretion and increased outflow) in response to adenyl cyclase activation $[27,37]$. Interestingly, the reduction of IOP by forskolin occurs through mechanisms that are not fully exploited by the existing hypotonizing glaucoma drugs. In fact, glaucoma patients, in whom the target pressure could not be reached even by the combination of three or four hypotonizing drugs, experienced a further decrease of their IOP when oral forskolin was added to their therapy [38]. Therefore, forskolin may have indirect beneficial neuroprotective effects on RGC by reduction of the IOP.

Beyond its action on IOP, forskolin may exert direct neuroprotection through different mechanisms. Neurotrophins, such as NGF and BDNF, have been found to be decreased in glaucoma [39-41]. In a rat model of experimental glaucoma, artificial elevation of IOP cripples the optic nerve head at the level of the lamina cribrosa, swelling nerve fibers and blocking the axonal flow of BDNF, while expression of the cognate receptor TrkB is increased at the optic nerve head [42]. Similar findings have also been reported in a spontaneous glaucoma model in the American Cocker Spaniel dog [43]. In this respect, forskolin could provide some degree of direct neuroprotection through the activation of paracrine signaling, since it has been shown to induce BDNF expression by astrocytes and vascular endothelial cells $[44,45]$ and to promote translocation of the cognate receptor TrkB to the neuron cell membrane [46]. Moreover, forskolin has been shown to be necessary for neuron cell survival in vitro $[47,48]$. Also, optic nerve regeneration that is promoted by oncomodulin needs cAMP elevation (as it can be promoted by forskolin) in order to work efficiently [49-51]. Finally, elevation of cAMP levels is known to reduce excitotoxic damage and to inhibit the resulting apoptotic cell death [52]. Forskolin has been shown to protect neuronal cell cultures from soman and sarin, which are toxic organophosphate chemicals [53], and to attenuate the adverse effects of long-term Schwann cell denervation on peripheral nerve regeneration in vivo [54].

From a clinical perspective, it was shown that oral treatment of POAG patients with a food supplement based on forskolin, besides decreasing the IOP (as expected), also improved their PERG amplitude, thus suggesting a positive effect on RGC survival and/or function [55].

\section{Forskolin with Homotaurine and L-Carnosine}

Recent data have shown an association between POAG and Alzheimer's disease [56], and the toxic accumulation of insoluble beta-amyloids may also occur in RGCs $[57,58]$.

Homotaurine has been reported to decrease the accumulation of amyloid plaques in neurons [59], and carnosine has shown extensive neuroprotective efficacy in a rat model of experimental glaucoma [60]. Therefore, based on these results, the synergic neuroprotective effect of forskolin, homotaurine, and L-carnosine has been investigated in a rat model of experimental glaucoma [61]. After the induction of retinal ischemia through the artificial increase of the IOP, forskolin, homotaurine, and L-carnosine have been injected in the rat's eye. Following the combined treatment, a synergic neuroprotective effect on RGC survival was reported, in association with the upregulation of the prosurvival pathway of PI3K/Akt [62] and the inhibition of the proapoptotic pathway linked to GSK-3 $\beta$ [63-65]. Such neuroprotective effect is also correlated with the reduction of calpain activity, known to be linked to neurodegenerative events $[66,67]$.

Support of the above comes from a recent clinical study [68] carried out on glaucomatous patients with IOP compensated by topical drugs, which evaluated the additional neuroprotective effect of the food supplement containing forskolin, homotaurine, carnosine, folic acid, vitamins B1, B2, and B6, and magnesium. Treatment with the food supplement resulted in a further significant decrease of the IOP (most likely due to forskolin) and an improvement of PERG amplitude and foveal sensitivity, parameters related to RGC function.

\section{Crocus sativus (Saffron)}

Saffron is derived from the pistils of Crocus sativus, a wellknown traditional Chinese medicine [69], and contains high concentrations of the carotenoids crocin and crocetin. Multiple divalent carbon bonds in saffron compounds confer their powerful radical scavenging and antioxidative properties [70-72]. It is likely because of this antioxidant effect on a clogged trabecular meshwork that high dose oral saffron treatment may further decrease IOP in POAG patients already undergoing different hypotonizing treatments [73].

More recent studies have highlighted the neuroprotective properties of saffron. In a rat model of continuous blue light exposure, saffron dietary supplement protects photoreceptors from photooxidative damage, maintaining both morphology and function [74]. Similar results against light-induced 


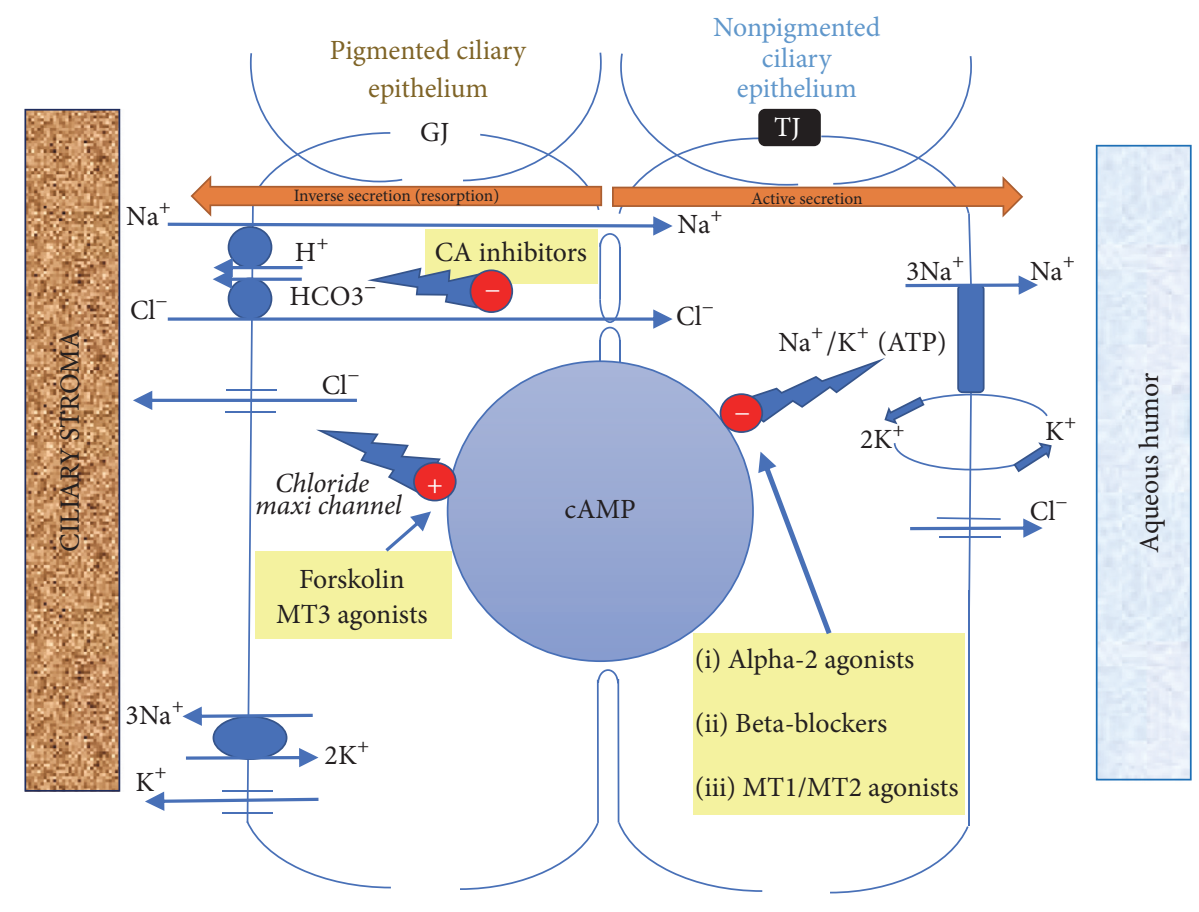

(a)
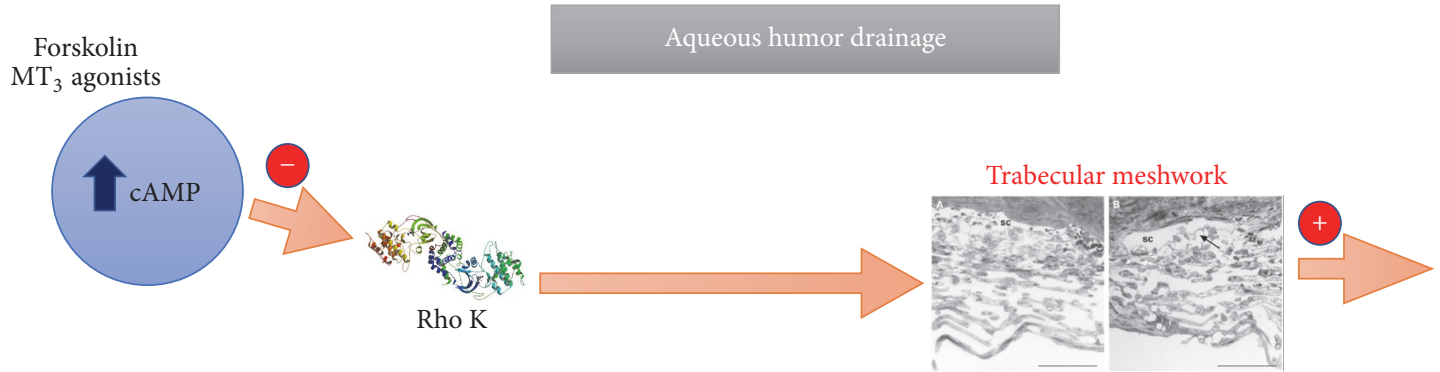

Permeation

(b)

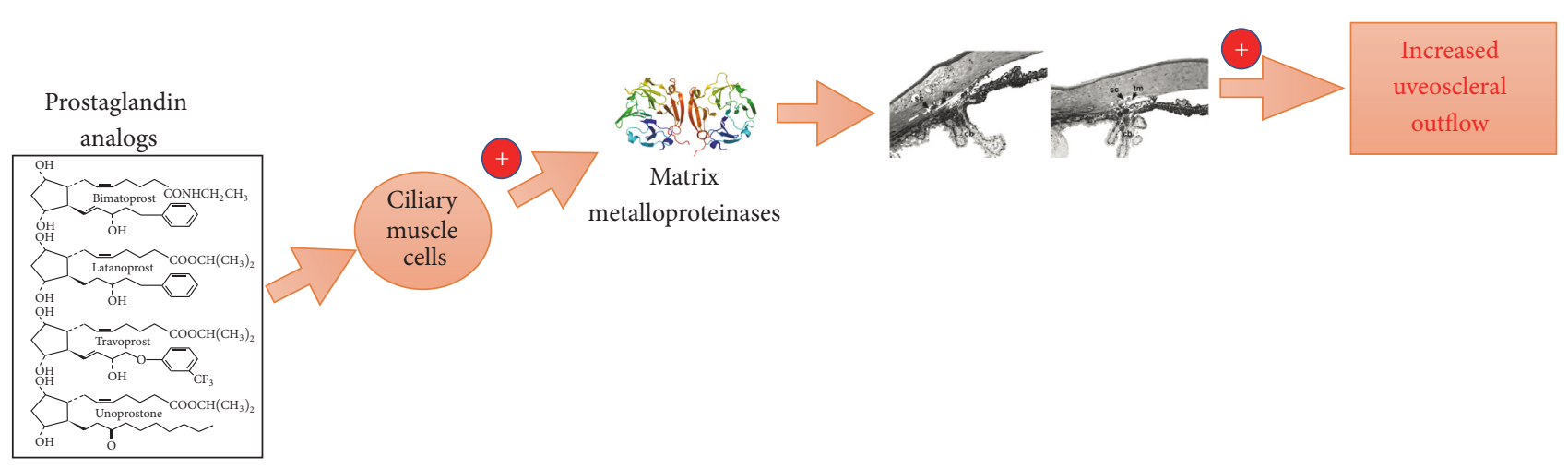

(c)

FIGURE 3: Regulation of IOP by different classes of molecules and mediators. (a) Central role of cAMP in the regulation of neat AH production. A decrease of cAMP in NPE ciliary cells appears to lead to a decreased efflux through the ATP-dependent Na+/K+ channel; an increase of ATP might trigger the activation of the chloride maxi channel in PE ciliary cells, leading to "inverse secretion" towards the stroma, finally reducing the AH influx into the anterior chamber. CA inhibitors work independently of cAMP and decrease carbonate exchange with the stroma, finally reducing chloride transit to the anterior chamber and water secretion. GJ: gap junctions; TJ: tight junctions; MT1,2,3: melatonin receptors; CA: carbonic anhydrase. (b) An increase of cAMP induced by forskolin or melatonin through the MT3 receptors may lead to inhibition of the Rho kinase, which in turn results in the disorganization of the TM cells cytoskeleton and finally to an increased TM outflow. (c) Prostaglandin analogs upregulate MMPs (matrix metalloproteases) which degrade extracellular proteins (mainly collagen) in the uveoscleral pathway, thus increasing $\mathrm{AH}$ outflow through this way. 
damage were obtained in mice and were attributed to the inhibition of caspase activity [75].

The main saffron components of interest for their associated biological activity are the carotenoid derivatives crocetin and crocin [69]. In a model of rat brain cerebral contusion, crocetin's protective effects were related to its proangiogenic and antiapoptotic activities [76].

Ocular hypertension, as well as the consequent reduced blood flow into the eye circulation, is the basis for the longstanding ischemic hypothesis of glaucoma [77, 78]. Crocin improves both the retinal and the choroidal blood flow in vivo and consequently facilitates retinal function recovery following IOP increase [79]. Qi et al. have demonstrated that injection of crocin in the eye prevented RGC apoptosis after retinal ischemia/reperfusion injury by involving the prosurvival PI3K/AKT signaling pathway. Furthermore, they have found that crocin increases the $\mathrm{Bcl}-2 / \mathrm{BAX}$ ratio, which contributes to the antiapoptotic effect of this molecule [80].

\section{Brimonidine}

Brimonidine is an adrenergic alpha-2 receptor $(\alpha 2 \mathrm{r})$ agonist, currently used in glaucoma therapy. Agonist mediated activation of $\alpha 2 \mathrm{r}$ leads to a decrease of cellular cAMP, which in turn results in decreased secretion of $\mathrm{AH}$ into the posterior chamber (Figure 3(a)) [34], thereby leading to a decreased IOP in the initial and long-term treatment of ocular hypertension and glaucoma [81-83].

Experimental studies have shown that brimonidine has also neuroprotective activity. In a rat model of axotomized eyes, intravitreal injection of brimonidine enhanced the survival and the electrophysiological activity of RGC, by activating the Trk-MAPK/ERK and Trk-PI3K signaling pathways [84]. Similarly, in a rat model of secondary neurodegeneration induced by partial crush of the optic nerve (thus independent of IOP elevation), the intraperitoneal administration of $\alpha 2 \mathrm{r}$ agonists (brimonidine, clonidine, and a synthetic compound AGN 191103) has been shown to be neuroprotective, whereas timolol injection had no effect [85]. In a retinal ischemia model, the intraperitoneal administration of brimonidine prevented the accumulation of toxic concentrations of extracellular glutamate and aspartate and preserved the ERG-b wave [86]. Similarly, systemic treatment with brimonidine prevented the elevation of N-methyl-Daspartate (NMDA) receptor expression in rat ischemic retinal injury induced by acute IOP elevation [87] and limited RGC death in both an isolated rat retina and an in vivo rabbit retinal excitotoxicity model, through the modulation of the NMDA receptor function [88].

Systemic administration of brimonidine has been shown to protect RGC in a rat model in which chronic ocular hypertension was induced by laser photocoagulation of the trabeculae [89].

Brimonidine has been shown to upregulate neurotrophic factors expression in the retina, such as fibroblast growth factor 2 (FGF2) and BDNF [90, 91]. The neuroprotective effects of brimonidine on RGC are also evident after topic ocular administration in adult rats [92].
Most recently, a new IOP independent neuroprotection mechanism has been identified for brimonidine and adrenergic $\alpha 2 \mathrm{r}$ agonists, which appears to inhibit the amyloidogenic pathway that leads to the formation of neurotoxic amyloid plaques, by stimulating the alternative nonamyloidogenic enzymes [58].

Clinical studies have shown that topical brimonidine improved the visual outcome of patients undergoing laser treatment for classic extrafoveal or juxtafoveal choroidal neovascularization treatment [93] and that brimonidine, but not timolol, topical therapy, improved contrast sensitivity of glaucoma patients after 3 months of treatment [94].

More recently, a long-term clinical study has indicated that topical brimonidine treatment may indeed protect the RGC of glaucomatous patients. The clinical comparison between brimonidine and timolol in preserving the visual function of NTG patients over a period of 4 years of observation has shown that, despite an identical effect on IOP, after 2 years, those patients treated with brimonidine were less likely to have disease progression than those treated with timolol [95].

\section{Cytidine-5' ${ }^{\prime}$-diphosphocholine (Citicoline)}

Citicoline is a naturally occurring cell endogenous compound, intermediate in the synthesis of membrane phospholipids such as phosphatidylcholine [96]. Experimental studies have shown that citicoline may indeed increase the synthesis of phospholipids in the CNS [97] and indicated a neuromodulator effect and a protective role of this molecule on RGC [98]. In rodent retinal cultures and animal models, citicoline triggered antiapoptotic effects, increased the retinal level of dopamine (one of the most important neurotransmitters involved in retinal and postretinal visual pathways) [99], and prevented the thinning of retinal nerve fiber layer [100]. However, whether dopamine itself works as a neuroprotectant for RGC is not clear yet, since no direct effects of dopamine on RGC survival have been reported.

Citicoline has been shown to protect the retina in vivo against kainate-induced neurotoxicity [101] and to rescue rat RGC following partial optic nerve crush [102].

A beneficial effect of citicoline oral supplement has been demonstrated in patients with nonarteritic ischemic optic neuropathy. At the end of the study, PERG, visual evoked potentials, and visual acuity were improved compared to pretreatment values and to a group of patients with no treatment during the same period [103].

Other clinical studies reported citicoline neurotrophic effects in POAG management [104-107]. The effect on the rate of progression of visual field loss ( $\mathrm{dB} /$ year) in subjects receiving citicoline oral supplementation was evaluated in a multicenter study on patients with progressive glaucoma. Patients receiving citicoline for two years showed a reduction in the mean rate of progression from $-1 \mathrm{~dB} /$ year to -0.15 $( \pm 0.3) \mathrm{dB} /$ year at the end of the study [108].

In another recent clinical study on POAG patients, Parisi et al. have shown that topical treatment with citicoline induces an enhancement of the retinal bioelectrical response (increase of PERG amplitude) with a consequent 
improvement of the bioelectrical activity of the visual cortex (shortening and increase of VEP implicit time and amplitude, resp.) [109].

\section{Melatonin and Agomelatine}

Melatonin is a hormone ubiquitously distributed in living systems, from bacteria to plants and animals. In mammals, including humans, it is secreted during darkness by the pineal gland and inhibited by light, so that it can modulate the body's sleep pattern. The pineal gland is the main source of melatonin, although other organs and cells such as skin, gastrointestinal tract, platelets, and lymphocytes can also make it [110]. Vertebrates' and mammals' retinas have also been shown to be able to synthesize melatonin, although confirmatory data are still needed for primates' retina [111]. Melatonin receptors (MT1, MT2, and to a lesser extent MT3) are consequently found in many tissues [112], including the eye, where they are well represented in retinal cells [111] and the ciliary epithelium [113].

The lipophilic nature of melatonin allows it to easily cross the hematoencephalic and hematoretinal barriers, thus reaching all tissues and the eye with good efficiency in a short time [114]. Melatonin can affect tissue metabolism and survival via receptor-independent and receptor-dependent mechanisms. The main receptor-independent activity is due to its strong antioxidant potential. Melatonin is a potent free radical scavenger and antioxidant, different from the other typical antioxidants. In fact, melatonin and its metabolites are able to neutralize numerous toxic oxygen and nitrogen reactive species (ROS and NOS, resp.) with high efficiency: one melatonin molecule has the capacity to scavenge a large variety of ROS/NOS, up to 10 molecules, versus the classic antioxidants that scavenge one or less of them. Therefore, melatonin is a more potent antioxidant than vitamins $\mathrm{E}$ and C [115]. Moreover, the large spectrum antioxidant activity of melatonin is potentiated by its regulatory activity on endogenous antioxidant and prooxidant enzymes, upregulating the former and downregulating the latter [116]. These activities designate melatonin as a neuroprotective agent in several neurodegenerative diseases, in which oxidative damage to neurons is a major player [117]. The efficacy of melatonin in preventing neuronal cell death and ameliorating Parkinson's disease (PD) symptoms has been demonstrated in animal models of PD [118].

In the eye, melatonin has been shown to protect human retinal pigment epithelial cells against oxidative stress [119] and to slow down photoreceptor degeneration in a mouse model of retinitis pigmentosa [120]. Moreover, the suppression of melatonin subtype receptor MT1 has been shown to decrease the viability of photoreceptors and RGCs $[121,122]$.

Glutamate accumulation in extracellular spaces can be potentially neurotoxic to the retina [123], and the impairment of glutamate transporter expression precedes the depression of glutamine synthase activity during ocular pressure loading [122]. In the hamster retina, it has been shown that melatonin may increase glutamate uptake and glutamine synthase activity, thus decreasing glutamate neurotoxicity [124].
Melatonin and its analogs have shown hypotonizing effects in both experimental animal models and glaucomatous patients [125-127]. Significant reductions of retinal melatonin levels were found in the rat model of glaucoma induced by chronic ocular hypertension [128]. The localization of melatonin receptors in the iris and ciliary processes strongly suggests that they are indeed involved in IOP regulation $[129,130]$, most likely through a mechanism that involves the putative MT3 receptors and a local increase in cAMP [131], similar to what has been described before for forskolin (Figure 3(a)). Correspondingly, preliminary clinical observations indicate a cooperative effect on IOP reduction by melatonin and forskolin (Pescosolido, personal communication).

Hypoxia has also been involved in the development of glaucoma [132-134]. Melatonin has shown neuroprotective effects against hypoxia-induced retinal ganglion cell death in neonatal rats [135].

Impairment of ocular blood flow is also a relevant player in the etiopathogenesis and progression of the glaucomatous optic neuropathy [132]. IOP or blood pressure circadian fluctuations cause an unstable oxygen supply, triggering further damage to RGCs [136]. Melatonin might contribute to the attenuation of these events, both on the IOP and on the blood flow control sides, since it is known to have vasoactive properties and shown to modulate arterial vasoconstriction [137].

Recognizing its beneficial antioxidant and ocular hypotensive properties, several melatonin related compounds, such as the synthetic analogs and the specific agonists of melatonin receptors, are under investigation [138]. Among the melatonin analogs, agomelatine is currently attracting interest for its pharmacological activities [110, 118, 127, 139141]. Agomelatine is a drug used in the treatment of major depressive disorders. It was developed as a nonselective MT1/MT2 agonist [142], and it was also revealed to be an antagonist of the 5-HT 2C serotonergic receptors [141, 143, 144].

Agomelatine has been shown to reduce rabbit's intraocular pressure under normotensive and hypertensive conditions [140]. In a recent clinical study, the hypotensive activity of oral agomelatine in eyes of POAG patients was revealed: agomelatine treatment resulted in a significant and stable hypotonizing effect after 15 and 30 days of treatment [127]. Its hypotonizing activity on IOP appears to follow its ability to activate both the MT2 and the MT3 receptors. In fact, specific antagonists to these receptors (4PPDOT and prazosin) could attenuate agomelatine effects on rabbits' IOP [140].

Agomelatine has also shown neuroprotective effects: it could decrease glutamate release, thus reducing its excitotoxic effect, in the rat hippocampus [145]. In vivo treatment with agomelatine reduces the chronic cerebral hypoperfusion responsible for vascular dementia and limits cholinergic dysfunction, oxidative stress, and tissue damage in mice [146]. The neuroprotective effects of agomelatine and melatonin against NMDA-receptor-mediated white matter lesions have been shown in a newborn mouse experimental model. Mice that received intraperitoneal agomelatine or melatonin had significant reductions in size of white matter cysts induced 
by the glutamatergic analog, when compared with controls [139].

\section{Ginkgo biloba Extract}

Ginkgo biloba is a native tree of China with various uses in traditional medicine and also as a source of food [147]. The leaf extract from Ginkgo biloba (GBE) is rich in biologically active ingredients (mainly flavonoids and terpenoids), which can scavenge free radicals and protect cells from lipid peroxidation [148-151]. More interestingly, the polyphenolic flavonoids that are richly present in GBE can act as antioxidants at the mitochondrial level (where other antioxidants cannot work), stabilizing mitochondrial membranes and improving their energetic balance specifically in neuronal cells $[152,153]$. This is an important contribution for glaucoma treatment, since mitochondrial dysfunction has been strongly implicated in POAG pathogenesis [154].

In several experimental studies, GBE has been shown to exert antioxidant and neuroprotective properties [155161]. Elevated levels of nitric oxide contribute significantly to the pathogenesis of ocular diseases [162]. Nitric oxide reacts with superoxides to form peroxynitrites [163], which cause nitrosylation of cellular proteins, DNA, and lipids, ultimately leading to RGC death [164]. It was demonstrated in vitro that GBE can scavenge nitric oxide [165] and possibly inhibit its production [166].

The protective activity of GBE on isolated rat retinas was evaluated on rats orally treated (versus untreated controls) with the extract for 10 days. Upon a challenge of the isolated retinas with an oxidant perfusion, GBE contrasted the decrease of ERG-b wave amplitude due to the oxidative damage [167].

The unstable oxygen supply to the retina and the optic nerve caused by high IOP, blood pressure fluctuations, or disturbed autoregulation also leads to increased oxidative stress, a main contributor to glaucomatous damage [136]. Beside its antioxidant properties, GBE also shows hemorheological and vasoactive effects, promoting erythrocytes deformability, decreasing fibrinogen levels, and improving blood viscosity and viscoelasticity [168], and increases microcirculation by improving the endothelium-dependent vasodilation [169]. Consistently, clinical observation has shown that GBE was able to significantly increase diastolic and systolic velocity in the ophthalmic artery (OA) of healthy volunteers [170]. Another clinical study evaluated the effects of GBE in NTG patients, in which vascular dysregulation appears to play a critical role. In a 4-month crossover design in a group of 27 patients with bilateral visual field damage resulting from NTG, a significant improvement in visual field parameters was recorded in association with oral delivery of $40 \mathrm{mg}$ GBE, three times daily, with no significant changes in IOP, blood pressure, or heart rate [171].

In another controlled clinical study on 52 POAG patients, those treated with GBE showed, after 3 months of treatment, a relevant decrease of endothelin-1 (ET1, responsible for peripheral vasoconstriction), resulting in increased flowdependent vasodilation. This was paralleled by a decrease of malondialdehyde-modified low-density lipoproteins and plasma malondialdehyde levels, indicating the activation of an antioxidant response and the attenuation of oxidative stress [172].

Apoptotic cell death is a hallmark of POAG damage and has been shown at the level of the trabecular meshwork [173] and the RGC layer [174]. GBE also shows antiapoptotic properties. Pheochromocytoma cells (PC12) treated with GBE were protected from mitochondrial damage induced by serum deprivation or by staurosporine through mechanisms that result in attenuated release of cytochrome-C and less DNA fragmentation, while DNA microarray assay results indicate that transcription of multiple apoptosis-related genes is either up- or downregulated in cells treated with GBE [175]. Moreover, GBE effects on mitochondria-dependent caspase pathway in cardiomyocytes exposed for 24 hours to hypoxia and four hours to reoxygenation resulted in inhibition of cytochrome-C release from mitochondria, thus decreasing caspase-3 activity and the resulting apoptotic cell death [176]. Finally, in an experimental in vivo study, it was demonstrated that GBE inhibited the apoptosis of RGC in guinea pigs after optic nerve transection, thus protecting their morphology and function [177].

\section{Coenzyme Q10}

Another even more specific agent targeting mitochondria for neuroprotection is the coenzyme Q10 (CoQ10), which is an essential membrane cofactor, with a strong antioxidant activity, in the mitochondrial respiratory chain $[178,179]$. It also appears to be able to modulate gene expression with anti-inflammatory effects [180]. CoQ10 has been suggested to have a beneficial role in several neurodegenerative diseases, like Alzheimer's disease, Parkinson's disease, Huntington's disease, chorea, and others, also including glaucoma [181]. In fact, in neurodegenerative diseases, external oxidative stress induces mitochondrial dysfunction, which in turn leads to the increase of ROS generation, and finally leads to apoptotic cell death of the neuronal cells [182]. CoQ10 has been shown to inhibit ROS generation, to maintain mitochondrial membrane potential during oxidative stress, and to reduce the amount of mitochondrial ROS generation in neuronal cell cultures [183]. Furthermore, the inhibition of oxidative stress by CoQ10 increases the mitochondrial mass and improves the bioenergetic function in primary optic nerve head rat astrocyte cultures [184].

Glutamate excitotoxicity and oxidative stress, besides IOP elevation, are known risk factors for POAG development and RGC death $[185,186]$. High levels of glutamate have been found in the retina of animal models of glaucoma $[187,188]$. Accordingly, it has been reported that CoQ10 protects retinal cells in vitro against oxidative stress induced by hydrogen peroxide and protects them in vivo after intravitreal injection of N-methyl-D-aspartate [189]. Intraocular administration of CoQ10 reduces the synaptic glutamate and delays apoptosis of rat RGC after retinal ischemia/reperfusion [190]. In a similar experiment, it was demonstrated that CoQ10 results in RGC protection after artificial elevation of extracellular glutamate [191]. Most recently, the role of oral CoQ10 supplement against the effects of glutamate excitotoxicity and oxidative 
stress on RGC degeneration has been addressed in the spontaneous DBA/2J mouse model of glaucoma [192]. After feeding the animals for six months with the supplement, results showed that CoQ10 preserved mitochondrial DNA content and the Tfam/OXPHOS complex IV protein expression in the retina of glaucomatous $\mathrm{DBA} / 2 \mathrm{~J}$ mice, triggering an improvement of RGC survival and morphological and functional preservation of the optic nerve head's axons.

Glaucoma is widely known to be associated with increased RGC apoptosis [193]. Caspase-7 plays a critical role in this process [194] since RGCs of mice knocked out for caspase-7 have been shown to be protected from apoptotic death [194]. More recent data also suggest an important role for Fas receptors and caspase-3-mediated apoptosis in the pathophysiology of glaucomatous neurodegeneration [195].

Along this line, the antiapoptotic activity of CoQ10 has been evaluated in a rat model of cultured RGCs exposed to external damage and in a mouse model of kainic acidinduced retinal damage. In these experimental models, CoQ10 significantly increased RGC viability by preventing caspase-3/7 activation [196].

Clinical studies also suggest that CoQ10 treatment may protect RGCs in human glaucoma. Topical administration of CoQ10 associated with vitamin $\mathrm{E}$ has been shown to positively affect retinal function in POAG patients. Patients treated with such association showed PERG improvement with consequent enhancement of the visual cortical responses [197].

Timolol is a nonselective beta-adrenergic receptor antagonist and is one of the main molecules indicated for glaucoma treatment. Unfortunately, in some cases, adverse cardiovascular effects can occur, and CoQ10 has been shown to be effective in reducing such systemic side effects induced by timolol $[198,199]$.

\section{Polyphenols: Epigallocatechin Gallate, Resveratrol, and Rutin}

Polyphenols are secondary plant metabolites generally synthesized from phenylalanine and used by plants in the defense against ultraviolet radiation or aggression by pathogens [200]. In the last decades, together with the realization that many pathologies, and aging itself, are caused by an excess of oxidative damage, there has been much attention to the health benefits of plant polyphenols (mainly those belonging to the class of flavonoids), due to their strong antioxidant properties [201].

\section{Epigallocatechin Gallate}

Catechins are flavanols, a subclass of flavonoids. They are the main components of green tea extract, among which epigallocatechin gallate (EGCG, also known as epigallocatechin-3gallate) is the most abundant. Catechins may act as radical scavengers, iron chelators, and modulators of prosurvival genes expression and the PKC signaling pathway [202, 203]. More recent studies indicate that these properties of green tea catechins do not fully explain their neuroprotective capacity and, in fact, a wider spectrum of intracellular molecular targets may be implicated, such as the regulation of calcium homeostasis [204] and the activation of mitogen-activated protein kinase (MAPK) [205, 206], phase II antioxidant detoxifying enzymes [207], and serine/threonine protein kinase AKT [208]. Moreover, it has been shown that EGCG promotes the processing of amyloid precursor protein (APP) via the nontoxic $\alpha$-secretase pathway [209] and reduces the formation of $\beta$-amyloid fibrils [210], which may be of particular relevance to both $\mathrm{AD}$ and glaucoma.

The neuroprotective effect of EGCG was demonstrated against the oxidative stress directly delivered to neural cells in vitro and in vivo in a mouse model of ischemia/reperfusion of the retina after artificial IOP elevation [211]. Along a similar line, it was shown that oral administration of EGCG protects RGCs from degeneration in a mouse model of chronic glaucoma obtained after microbeads injection in the anterior chamber [212] and in the optic nerve crush rat model [213]. Intravitreal injection of oxidants such as sodium nitroprusside (which generates NO spontaneously) triggers significant photoreceptor apoptosis with the rest of the retina relatively unaffected $[214,215]$. When EGCG is injected into the rat eye together with sodium nitroprusside, its detrimental influence on retinal photoreceptors was attenuated [216].

The pharmacokinetics of EGCG have been addressed by HPLC analysis, showing that, after a single oral administration, EGCG is widely distributed in mouse tissues and reaches the central nervous system in a short time $(6 \mathrm{~h})$; a second administration after a $6 \mathrm{~h}$ interval enhances tissue levels four to six times above that of a single administration [217].

EGCG is nongenotoxic, even when administered to animals at doses that are significantly higher than those intended for humans [218].

Clinical efficacy of a short-term oral supplementation of EGCG has been studied by PERG analysis (addressing the electrical activity of RGC), showing that the treatment might favorably influence the inner retinal function in human eyes of glaucomatous patients with early to moderately advanced damage [219].

\section{Resveratrol}

Resveratrol belongs to a class of polyphenolic compounds called stilbenes. Some plants (notably red grapes) produce resveratrol and other stilbenoids in response to stress, injury, fungal infection, or ultraviolet (UV) radiation [220]. Besides its own antioxidant activity, more evident in the test tube than in vivo [221], resveratrol has been shown to induce several antioxidant enzymes, including superoxide dismutase (SOD), thioredoxin, glutathione peroxidase-1, heme oxygenase-1, and catalase [222]. Accordingly, experimental evidence has confirmed that resveratrol has anti-inflammatory, antioxidant, and antiapoptotic activities and a beneficial effect in preventing or slowing down a wide range of age-related diseases [223-225].

Resveratrol's neuroprotective effects appear to be mainly due to some of its physiological effects, such as stimulation of neurogenesis and microvessel formation as shown in aging rats [226]; stimulation of $\beta$-amyloid peptide clearance as shown in a transgenic AD mouse model [227]; inhibition of 
neuroinflammation, as shown in the inflammatory response in a mouse model of cerebral amyloid deposition [228]; and finally the reduction of mitochondrial oxidative stress as shown in vitro in neuroblastoma cells [229] and in vivo in the age-related cognitive dysfunction in old rats [230]. The neuroprotective effects of resveratrol dietary supplement were evaluated on the expression of markers for inflammation, oxidative damage, and cellular senescence in primary trabecular meshwork cells exposed to chronic oxidative stress. Results showed that resveratrol prevented the production of intracellular reactive oxygen species (ROS) and inflammatory markers (such as IL-1-alpha, IL-6, IL8, and ELAM-1) [231]. In another study, the effects of the neuroprotective agents riluzole and resveratrol (each with different neuroprotection mechanisms), when administered alone or in combination, were evaluated on the survival of RGC in a rat model of glaucoma. Results indicated that RGCs were significantly preserved in all treatment groups compared to vehicle-only treated control animals and that (as expected) the association of the two neuroprotective agents gave better results than each one alone [232]. In a mouse model of mechanical optic nerve injury, long-term diet supplementation with resveratrol has been shown to delay RGC dendrite remodeling and loss [233]. In another recent work, the hypotensive effect of topical trans-resveratrol was evaluated in rats with steroid-induced ocular hypertension [234]. The maximum hypotensive effect was obtained with a $0.2 \%$ concentration of resveratrol and was evident both in normotensive animals and even to a greater extent in the hypertensive ones. Such effect disappeared in the presence of subtype $A_{1}$ adenosine receptor antagonist, which was then considered responsible for the effect itself, as already known by previous experimental data [235]. In another in vivo study, resveratrol has been shown to protect rat RCGs against retinal ischemia/reperfusion injury induced by high intraocular pressure. The protection of resveratrol in these experiments was associated with the downregulation of the expression levels of matrix metalloproteinase-9, inducible nitric oxide, and heme oxygenase-1 [236].

\section{Rutin}

Rutin (also known as vitamin $\mathrm{P}$ or rutoside) is a flavonol glycoside found in many plants and fruits [237], resulting from the combination of the flavonol quercetin and the disaccharide rutinose. Indeed, upon oral administration, the disaccharide is cleaved, and quercetin is liberated, so that rutin's anti-inflammatory actions appear to be due to the quercetin-mediated effects via the inhibition of the proinflammatory chain triggered by TNF- $\alpha$-induced NF- $\kappa \mathrm{B}$ activation [238].

Rutin has been shown to possess multiple pharmacological activities [239]. Two recent clinical studies have shown that oral administration of a food supplement containing rutin potentiates the hypotonizing effects of pharmacological treatments. It contributes to a better control and a further, although small, reduction of the IOP in POAG patients $[38,240]$. Another clinical study showed that oral treatment with an association of forskolin and rutin can blunt the IOP spikes and avoid the damage that may occur after Nd:YAG laser iridotomy for the prevention of primary closed-angle glaucoma [241]. Furthermore, the association of forskolin and rutin has been shown to improve the symptoms of discomfort in glaucomatous patients suffering from dry eye induced by the long-term use of eye drops preserved with BAK [242].

Concerning the neuroprotective activity of rutin, different mechanisms have been suggested using both in vivo and in vitro models of neurodegeneration [243-245]. These include the reduction of possibly toxic nitric oxide levels, the inhibition of apoptotic triggers, and the upregulation of neurotrophic factors. In rat pheochromocytoma cells, rutin modulated several neuroprotective genes, including tyrosine hydroxylase, and was able to suppress caspase- 3 activity [246]. Under hypoxic and glutamate stress conditions, rutin significantly increased the survival rate of neonatal rat RGCs by inhibiting the induction of proapoptotic caspase-3 and calpain [247]. The neuroprotective effects of rutin on the diabetic rat retina have been shown, likely contributed by rutin decreasing both activity and expression of caspase-3 and increasing the protein expression of the survival factor Bcl-2 [248].

Optimal levels of neurotrophic factors are necessary for normal neuronal functions such as synaptic activity and neuronal survival [249]. Rutin treatment significantly increased the levels of both BDNF and NGF in the retina of diabetic rats and activated BDNF and NGF gene expression in the hippocampus and brain of rodents $[237,250]$.

\section{Conclusions}

It is common knowledge that glaucoma is a slowly progressing neurodegenerative disease, in which RGCs are primarily affected. Several pathogenic mechanisms appear to be involved in glaucoma disease such as IOP elevation, ischemia/reperfusion, oxidative stress, neurotrophic growth factor deprivation, activation of autoimmunity, and glutamate neurotoxicity. Even if IOP control remains the gold standard for the pharmacological approach, it is clear from emerging research, as described in this review, that several molecules may interfere with the process leading to POAG progression, protecting RGC and preventing or at least delaying their apoptotic death, independently of IOP control.

Two main mechanisms emerge as critical targets for neuroprotection: (i) those linked to cAMP and (ii) those controlling oxidative stress and mitochondrial dysfunction.

cAMP is a second messenger involved in many different cellular pathways. It is pivotal in controlling $\mathrm{AH}$ secretion/reabsorption [251] and in regulating neurotrophin gene expression for RGC survival [252]. In fact, hypotonizing drugs such as alpha-agonists and beta-blockers plus forskolin and melatonin (although with different mechanisms) all impinge on cAMP production, neat $\mathrm{AH}$ secretion, and neuroprotection.

Oxidative stress is the main target of the other neuroprotective agents, including melatonin, described in this review.

Notably, the three compounds discussed here (namely, brimonidine, forskolin, and melatonin) all contribute at the same time to IOP control and neuroprotection, so that the 
association of these molecules together with current glaucoma therapies could lead to additional benefits for patients. Ideally, the best treatment for a glaucoma patient would include a hypotonizing agent together with a neuroprotective one spanning several different molecular neurotoxic mechanisms. Melatonin and/or forskolin appear to be good candidates to be associated with a classical hypotonizing drug, preferably brimonidine, considering its own neuroprotective effects.

Longer-term randomized clinical trials (RCT) are of course needed in order to prove this hypothesis, which opens an old, still unanswered problem about the role of RCT in neuroprotection. Indeed, a critical look at ways to take advantage of the current scientific and technological knowledge to run a reliable and affordable RCT could be an amenable and highly needed subject for a consensus conference and perhaps a future review paper.

\section{Conflicts of Interest}

Dario Rusciano and Salvatore Pezzino are full-time employees of Sooft Italia S.p.A., an ophthalmic pharmaceutical company belonging to Fidia Pharma Group, which develops and commercializes food supplements for neuroprotection in glaucoma.

\section{References}

[1] H. A. Quigley, “Glaucoma," The Lancet, vol. 377, no. 9774, pp. 1367-1377, 2011.

[2] The AGIS Investigators, "The Advanced Glaucoma Intervention Study (AGIS): 7. The relationship between control of intraocular pressure and visual field deterioration," American Journal of Ophthalmology, vol. 130, no. 4, pp. 429-440, 2000.

[3] S. W. Jin and S. Y. Noh, "Long-term clinical course of normaltension glaucoma: 20 years of experience," Journal of Ophthalmology, vol. 2017, 6 pages, 2017.

[4] R. N. Weinreb, T. Aung, and F. A. Medeiros, "The pathophysiology and treatment of glaucoma: a review," The Journal of the American Medical Association, vol. 311, no. 18, pp. 1901-1911, 2014.

[5] C. Nucci, R. Tartaglione, L. Rombolà, L. A. Morrone, E. Fazzi, and G. Bagetta, "Neurochemical evidence to implicate elevated glutamate in the mechanisms of high intraocular pressure (IOP)-induced retinal ganglion cell death in rat," NeuroToxicology, vol. 26, no. 5, pp. 935-941, 2005.

[6] J. P. Kersey and D. C. Broadway, "Corticosteroid-induced glaucoma: a review of the literature," Eye, vol. 20, no. 4, pp. 407416, 2006.

[7] D. Gupta and P. P. Chen, "Glaucoma," Am Fam Physician, vol. 93, no. 8, pp. 668-74, 2016.

[8] A. J. Tatham, R. N. Weinreb, and F. A. Medeiros, "Strategies for improving early detection of glaucoma: the combined structure-function index," Clinical Ophthalmology, vol. 8, pp. 611-621, 2014.

[9] K. Abu-Amero, A. A. Kondkar, and K. V. Chalam, "An updated review on the genetics of primary open angle glaucoma," International Journal of Molecular Sciences, vol. 16, no. 12, pp. 28886-28911, 2015.
[10] H. Diekmann and D. Fischer, "Glaucoma and optic nerve repair," Cell and Tissue Research, vol. 353, no. 2, pp. 327-337, 2013.

[11] M. Seki and S. A. Lipton, "Targeting excitotoxic/free radical signaling pathways for therapeutic intervention in glaucoma," Progress in Brain Research, vol. 173, pp. 495-510, 2008.

[12] P. Geraldine, B. Brijit Sneha, R. Elanchezhian et al., "Prevention of selenite-induced cataractogenesis by acetyl-1-carnitine: An experimental study," Experimental Eye Research, vol. 83, no. 6, pp. 1340-1349, 2006.

[13] S. E. Ohia, C. A. Opere, and A. M. Leday, "Pharmacological consequences of oxidative stress in ocular tissues," Mutation Research - Fundamental and Molecular Mechanisms of Mutagenesis, vol. 579, no. 1-2, pp. 22-36, 2005.

[14] A. Izzotti, A. Bagnis, and S. C. Saccà, "The role of oxidative stress in glaucoma," Mutation Research-Reviews in Mutation Research, vol. 612, no. 2, pp. 105-114, 2006.

[15] N. Toda and M. Nakanishi-Toda, "Nitric oxide: ocular blood flow, glaucoma, and diabetic retinopathy," Progress in Retinal and Eye Research, vol. 26, no. 3, pp. 205-238, 2007.

[16] S. P. Richer and R. C. Rose, "Water soluble antioxidants in mammalian aqueous humor: Interaction with UV B and hydrogen peroxide," Vision Research, vol. 38, no. 19, pp. 28812888, 1998.

[17] D. Gherghel, H. R. Griffiths, E. J. Hilton, I. A. Cunliffe, and S. L. Hosking, "Systemic reduction in glutathione levels occurs in patients with primary open-angle glaucoma," Investigative Ophthalmology \& Visual Science, vol. 46, no. 3, pp. 877-883, 2005.

[18] N. Fan, P. Wang, L. Tang, and X. Liu, "Ocular Blood Flow and Normal Tension Glaucoma," BioMed Research International, vol. 2015, Article ID 308505, 2015.

[19] A. C. Gauthier and J. Liu, "Neurodegeneration and Neuroprotection in Glaucoma," Yale Journal of Biology and Medicine, vol. 89, no. 1, pp. 73-79, 2016.

[20] N. Tripathi, N. Saini, and S. Tiwari, "Morphological and molecular characterization of endangered medicinal plant species coleus forskohlii collected from central India," Journal of Crop Science and Biotechnology, vol. 16, no. 4, pp. 253-261, 2013.

[21] K. B. Seamon and J. W. Daly, "Forskolin: A unique diterpene activator of cyclic AMP-generating systems," Journal of Cyclic Nucleotide Research, vol. 7, no. 4, pp. 201-204, 1981.

[22] M. L. Sears, "Regulation of aqueous flow by the adenylate cyclase receptor complex in the ciliary epithelium," American Journal of Ophthalmology, vol. 100, no. 1, pp. 194-198, 1985.

[23] M. J. Busch, K. Kobayashi, P. F. Hoyng, and T. W. Mittag, "Adenylyl cyclase in human and bovine trabecular meshwork," Invest Ophthalmol Vis Sci, vol. 34, no. 10, pp. 3028-3034, 1993.

[24] S. P. Bartels, S. R. Lee, and A. H. Neufeld, "Forskolin stimulates cyclic AMP synthesis, lowers intraocular pressure and increases outflow facility in rabbits," Current Eye Research, vol. 2, no. 10, pp. 673-681, 1982.

[25] J. Caprioli and M. Sears, "Forskolin lowers intraocular pressure in rabbits, monkeys, and man," Lancet, vol. 1, no. 8331, pp. 958960, 1983.

[26] J. Caprioli and M. Sears, "Combined effect of forskolin and acetazolamide on intraocular pressure and aqueous flow in rabbit eyes," Experimental Eye Research, vol. 39, no. 1, pp. 47-50, 1984.

[27] J. Caprioli, M. Sears, L. Bausher, D. Gregory, and A. Mead, "Forskolin lowers intraocular pressure by reducing aqueous inflow," Investigative Ophthalmology \& Visual Science, vol. 25, no. 3, pp. 268-277, 1984. 
[28] B. R. Smith, R. N. Gaster, I. H. Leopold, and L. D. Zeleznick, "Forskolin, a Potent Adenylate Cyclase Activator, Lowers Rabbit Intraocular Pressure," JAMA Ophtalmology, vol. 102, no. 1, pp. 146-148, 1984.

[29] S. P. Bartels, S. R. Lee, and A. H. Neufeld, "The effects of forskolin on cyclic AMP, intraocular pressure and aqueous humor formation in rabbits," Current Eye Research, vol. 6, no. 2, pp. 307-320, 1987.

[30] T. Shibata, H. Mishima, and T. Kurokawa, "Ocular pigmentation and intraocular pressure response to forskolin," Current Eye Research, vol. 7, no. 7, pp. 667-674, 1988.

[31] S. Matsumoto, T. Yamashita, M. Araie, S. Kametani, T. Hosokawa, and M. Takase, "The ocular penetration of topical forskolin and its effects on intraocular pressure, aqueous flow rate and cyclic AMP level in the rabbit eye," Japanese Journal of Ophthalmology, vol. 34, no. 4, pp. 428-435, 1990.

[32] S. Zeng, B. Shen, L. Wen et al., "Experimental studies of the effect of Forskolin on the lowering of intraocular pressure," Yan Ke Xue Bao, vol. 11, no. 3, pp. 173-176, 1995.

[33] C.-W. Do, K. Peterson-Yantorno, C. H. Mitchell, and M. M. Civan, "cAMP-activated maxi-Cl- channels in native bovine pigmented ciliary epithelial cells," American Journal of Physiology-Cell Physiology, vol. 287, no. 4, pp. C1003-C1011, 2004.

[34] W. H. Morgan and D. Yu, "Surgical management of glaucoma: a review," Clinical \& Experimental Ophthalmology, vol. 40, no. 4, pp. 388-399, 2012.

[35] X. Shen, T. Koga, B.-C. Park, N. SundarRaj, and B. Y. J. T. Yue, "Rho GTPase and cAMP/protein kinase A signaling mediates myocilin-induced alterations in cultured human trabecular meshwork cells," The Journal of Biological Chemistry, vol. 283, no. 1, pp. 603-612, 2008.

[36] P. L. Kaufman, "Enhancing trabecular outflow by disrupting the actin cytoskeleton, increasing uveoscleral outflow with prostaglandins, and understanding the pathophysiology of presbyopia. Interrogating Mother Nature: asking why, asking how, recognizing the signs, following the trail," Experimental Eye Research, vol. 86, no. 1, pp. 3-17, 2008.

[37] J. Caprioli and M. Sears, "The adenylate cyclase receptor complex and aqueous humor formation," Yale Journal of Biology and Medicine, vol. 57, no. 3, pp. 283-300, 1984.

[38] M. Vetrugno, M. G. Uva, V. Russo et al., "Oral administration of forskolin and rutin contributes to intraocular pressure control in primary open angle glaucoma patients under maximum tolerated medical therapy," Journal of Ocular Pharmacology and Therapeutics, vol. 28, no. 5, pp. 536-541, 2012.

[39] H. Wang, R. Wang, T. Thrimawithana et al., “The Nerve Growth Factor Signaling and Its Potential as Therapeutic Target for Glaucoma," BioMed Research International, vol. 2014, Article ID 759473, 2014.

[40] A. Ghaffariyeh, N. Honarpisheh, M. H. Heidari, S. Puyan, and F. Abasov, "Brain-derived neurotrophic factor as a biomarker in primary open-angle glaucoma," Optometry and Vision Science, vol. 88, no. 1, pp. 80-85, 2011.

[41] V. Sposato, V. Parisi, L. Manni et al., "Glaucoma alters the expression of NGF and NGF receptors in visual cortex and geniculate nucleus of rats: effect of eye NGF application," Vision Research, vol. 49, no. 1, pp. 54-63, 2009.

[42] M. E. Pease, S. J. McKinnon, H. A. Quigley, L. A. KerriganBaumrind, and D. J. Zack, "Obstructed axonal transport of
BDNF and its receptor TrkB in experimental glaucoma," Investigative Ophthalmology \& Visual Science, vol. 41, no. 3, pp. 764$774,2000$.

[43] S. Iwabe, N. A. Moreno-Mendoza, F. Trigo-Tavera, C. Crowder, and G. A. García-Sánchez, "Retrograde axonal transport obstruction of brain-derived neurotrophic factor (BDNF) and its $\operatorname{TrkB}$ receptor in the retina and optic nerve of American Cocker Spaniel dogs with spontaneous glaucoma," Veterinary Ophthalmology, vol. 10, no. 1, pp. 12-19, 2007.

[44] D. M. Juric, D. Loncar, and M. Carman-Krzan, "Noradrenergic stimulation of BDNF synthesis in astrocytes: Mediation via $\alpha 1$ and $\beta 1 / \beta 2$-adrenergic receptors," Neurochemistry International, vol. 52, no. 1-2, pp. 297-306, 2008.

[45] T. Nakahashi, H. Fujimura, C. A. Altar et al., "Vascular endothelial cells synthesize and secrete brain-derived neurotrophic factor," FEBS Letters, vol. 470, no. 2, pp. 113-117, 2000.

[46] A. Meyer-Franke, G. A. Wilkinson, A. Kruttgen et al., "Depolarization and cAMP elevation rapidly recruit TrkB to the plasma membrane of CNS neurons," Neuron, vol. 21, no. 4, pp. 681-693, 1998.

[47] A. Meyer-Franke, M. R. Kaplan, F. W. Pfieger, and B. A. Barres, "Characterization of the signaling interactions that promote the survival and growth of developing retinal ganglion cells in culture," Neuron, vol. 15, no. 4, pp. 805-819, 1995.

[48] M. G. Hanson Jr., S. Shen, A. P. Wiemelt, F. Arthur McMorris, and B. A. Barres, "Cyclic AMP elevation is sufficient to promote the survival of spinal motor neurons in vitro," The Journal of Neuroscience, vol. 18, no. 18, pp. 7361-7371, 1998.

[49] R. Harel, C. A. Iannotti, D. Hoh, M. Clark, J. Silver, and M. P. Steinmetz, "Oncomodulin affords limited regeneration to injured sensory axons in vitro and in vivo," Experimental Neurology, vol. 233, no. 2, pp. 708-716, 2012.

[50] T. Kurimoto, Y. Yin, K. Omura et al., "Long-distance axon regeneration in the mature optic nerve: contributions of oncomodulin, cAMP, and pten gene deletion," The Journal of Neuroscience, vol. 30, no. 46, pp. 15654-15663, 2010.

[51] Y. Yin, M. T. Henzl, B. Lorber et al., "Oncomodulin is a macrophage-derived signal for axon regeneration in retinal ganglion cells," Nature Neuroscience, vol. 9, no. 6, pp. 843-852, 2006.

[52] H. Nishihara, S. Kizaka-Kondoh, P. A. Insel, and L. Eckmann, "Inhibition of apoptosis in normal and transformed intestinal epithelial cells by cAMP through induction of inhibitor of apoptosis protein (IAP)-2," Proceedings of the National Acadamy of Sciences of the United States of America, vol. 100, no. 15, pp. 8921-8926, 2003.

[53] B. F. Curtin, N. Pal, R. K. Gordon, and M. P. Nambiar, "Forskolin, an inducer of cAMP, up-regulates acetylcholinesterase expression and protects against organophosphate exposure in neuro 2A cells," Molecular and Cellular Biochemistry, vol. 290, no. 1-2, pp. 23-32, 2006.

[54] O. A. R. Sulaiman and T. Gordon, "Transforming growth factor$\beta$ and forskolin attenuate the adverse effects of long-term Schwann cell denervation on peripheral nerve regeneration in vivo," Glia, vol. 37, no. 3, pp. 206-218, 2002.

[55] D. Sisto, N. Lavermicocca, D. Errico, and D. Rusciano, "Oral Administration of Forskolin and Rutin Contributes to Reduce Intraocular Pressure and Improve PERG (Pattern Electroretinogram) Amplitude in Glaucomatous Patients," JSM Biotechnol Bioeng, vol. 2, no. 1, p. 8, 2013.

[56] M. Cesareo, A. Martucci, E. Ciuffoletti et al., "Association between alzheimer's disease and glaucoma: A study based 
on heidelberg retinal tomography and frequency doubling technology perimetry," Frontiers in Neuroscience, vol. 9, article no. $479,2015$.

[57] L. Guo, T. E. Salt, V. Luong et al., "Targeting amyloid- $\beta$ in glaucoma treatment," Proceedings of the National Acadamy of Sciences of the United States of America, vol. 104, no. 33, pp. 13444-13449, 2007.

[58] S. Nizari, L. Guo, B. M. Davis et al., "Non-amyloidogenic effects of $\alpha 2$ adrenergic agonists: Implications for brimonidinemediated neuroprotection," Cell Death \& Disease, vol. 7, no. 12, Article ID e2514, 2016.

[59] C. Caltagirone, L. Ferrannini, N. Marchionni, G. Nappi, G. Scapagnini, and M. Trabucchi, "The potential protective effect of tramiprosate (homotaurine) against Alzheimer's disease: a review," Aging Clinical and Experimental Research, vol. 24, no. 6, pp. 580-587, 2012.

[60] Y.-S. Ji, J.-W. Park, H. Heo, J.-S. Park, and S.-W. Park, “The neuroprotective effect of carnosine ( $\beta$-Alanyl-1-Histidine) on retinal ganglion cell following ischemia-reperfusion injury," Current Eye Research, vol. 39, no. 6, pp. 634-641, 2014.

[61] R. Russo, A. Adornetto, F. Cavaliere et al., "Intravitreal injection of forskolin, homotaurine, and L-carnosine affords neuroprotection to retinal ganglion cells following retinal ischemic injury," Molecular Vision, vol. 21, pp. 718-729, 2015.

[62] R. Russo, F. Cavaliere, L. Berliocchi et al., "Modulation of pro-survival and death-associated pathways under retinal ischemia/reperfusion: Effects of NMDA receptor blockade," Journal of Neurochemistry, vol. 107, no. 5, pp. 1347-1357, 2008.

[63] Z. Li, L. Ma, X. Chen et al., "Glycogen synthase kinase-3: a key kinase in retinal neuron apoptosis in early diabetic retinopathy," Molecular Medicine Reports, vol. 127, no. 19, pp. 3464-3470, 2014.

[64] M. Hetman and Z. Xia, "Signaling pathways mediating antiapoptotic action of neurotrophins," Acta Neurobiol Exp (Wars), vol. 60, no. 4, pp. 531-545, 2000.

[65] E. Beurel and R. S. Jope, "The paradoxical pro- and antiapoptotic actions of GSK3 in the intrinsic and extrinsic apoptosis signaling pathways," Progress in Neurobiology, vol. 79, no. 4, pp. 173-189, 2006.

[66] R. A. Nixon, "The calpains in aging and aging-related diseases," Ageing Research Reviews, vol. 2, no. 4, pp. 407-418, 2003.

[67] K. E. Saatman, B. Abai, A. Grosvenor, C. K. Vorwerk, D. H. Smith, and D. F. Meaney, "Traumatic axonal injury results in biphasic calpain activation and retrograde transport impairment in mice," Journal of Cerebral Blood Flow \& Metabolism, vol. 23, no. 1, pp. 34-42, 2003.

[68] M. G. Mutolo, G. Albanese, D. Rusciano, and N. Pescosolido, "Oral Administration of Forskolin, Homotaurine, Carnosine, and Folic Acid in Patients with Primary Open Angle Glaucoma: Changes in Intraocular Pressure, Pattern Electroretinogram Amplitude, and Foveal Sensitivity," Journal of Ocular Pharmacology and Therapeutics, vol. 32, no. 3, pp. 178-183, 2016.

[69] R. Srivastava, H. Ahmed, R. Dixit, Dharamveer, and S. Saraf, "Crocus sativus L.: A comprehensive review," Pharmacognosy Reviews, vol. 4, no. 8, pp. 200-208, 2010.

[70] A. N. Assimopoulou, Z. Sinakos, and V. P. Papageorgiou, "Radical scavenging activity of Crocus sativus L. extract and its bioactive constituents," Phytotherapy Research, vol. 19, no. 11, pp. 997-1000, 2005.

[71] T. Ochiai, H. Shimeno, K.-I. Mishima et al., "Protective effects of carotenoids from saffron on neuronal injury in vitro and in vivo," Biochimica et Biophysica Acta (BBA) - General Subjects, vol. 1770, no. 4, pp. 578-584, 2007.

[72] H. Hosseinzadeh, H. R. Sadeghnia, T. Ziaee, and A. Danaee, "Protective effect of aqueous saffron extract (Crocus sativus L.) and crocin, its active constituent, on renal ischemiareperfusion-induced oxidative damage in rats," Journal of Pharmacy \& Pharmaceutical Sciences, vol. 8, no. 3, pp. 387-393, 2005.

[73] M. H. J. Bonyadi, S. Yazdani, and S. Saadat, "The ocular hypotensive effect of saffron extract in primary open angle glaucoma: A pilot study," BMC Complementary and Alternative Medicine, vol. 14, no. 1, article no. 399, 2014.

[74] R. Maccarone, S. Di Marco, and S. Bisti, "Saffron supplement maintains morphology and function after exposure to damaging light in mammalian retina," Investigative Ophthalmology \& Visual Science, vol. 49, no. 3, pp. 1254-1261, 2008.

[75] M. Yamauchi, K. Tsuruma, S. Imai et al., "Crocetin prevents retinal degeneration induced by oxidative and endoplasmic reticulum stresses via inhibition of caspase activity," European Journal of Pharmacology, vol. 650, no. 1, pp. 110-119, 2011.

[76] X. Bie, Y. Chen, X. Zheng, and H. Dai, "The role of crocetin in protection following cerebral contusion and in the enhancement of angiogenesis in rats," Fitoterapia, vol. 82, no. 7, pp. 9971002, 2011.

[77] A. P. Cherecheanu, G. Garhofer, D. Schmidl, R. Werkmeister, and L. Schmetterer, "Ocular perfusion pressure and ocular blood flow in glaucoma," Current Opinion in Pharmacology, vol. 13, no. 1, pp. 36-42, 2013.

[78] H. Ates, O. Uretmen, R. Killi, C. Akkin, and K. Andac, "Relationship between ocular perfusion pressure and retrobulbar blood flow in patients with glaucoma with progressive damage," American Journal of Ophthalmology, vol. 132, no. 4, pp. 598-599, 2001.

[79] B. Xuan, Y.-H. Zhou, N. Li, Z.-D. Min, and G. C. Y. Chiou, "Effects of crocin analogs on ocular blood flow and retinal function," Journal of Ocular Pharmacology and Therapeutics, vol. 15, no. 2, pp. 143-152, 1999.

[80] Y. Qi, L. Chen, L. Zhang, W.-B. Liu, X.-Y. Chen, and X.-G. Yang, "Crocin prevents retinal ischaemia/reperfusion injury-induced apoptosis in retinal ganglion cells through the PI3K/AKT signalling pathway," Experimental Eye Research, vol. 107, pp. 4451, 2013.

[81] A. M. Carlsson, B. C. Chauhan, A. A. Lee, and R. P. Leblanc, "The effect of brimonidine tartrate on retinal blood flow in patients with ocular hypertension," American Journal of Ophthalmology, vol. 129, no. 3, pp. 297-301, 2000.

[82] Y. Lachkar, C. Migdal, and S. Dhanjil, "Effect of brimonidine tartrate on ocular hemodynamic measurements," JAMA Ophtalmology, vol. 116, no. 12, pp. 1591-1594, 1998.

[83] S. Sharma, S. Trikha, S. A. Perera, and T. Aung, "Clinical effectiveness of brinzolamide $1 \%$-brimonidine $0.2 \%$ fixed combination for primary open-angle glaucoma and ocular hypertension," Clinical Ophthalmology, vol. 9, pp. 2201-2207, 2015.

[84] M. Yukita, K. Omodaka, S. Machida et al., "Brimonidine Enhances the Electrophysiological Response of Retinal Ganglion Cells through the Trk-MAPK/ERK and PI3K Pathways in Axotomized Eyes," Current Eye Research, vol. 42, no. 1, pp. 125133, 2017.

[85] E. Yoles, L. A. Wheeler, and M. Schwartz, "Alpha2-adrenoreceptor agonists are neuroprotective in a rat model of optic nerve degeneration," Invest Ophthalmol Vis Sci, vol. 40, no. 1, pp. 6573, 1999. 
[86] J. E. Donello, E. U. Padillo, M. L. Webster, L. A. Wheeler, and D. W. Gil, " $\alpha 2$-adrenoceptor agonists inhibit vitreal glutamate and aspartate accumulation and preserve retinal function after transient ischemia," The Journal of Pharmacology and Experimental Therapeutics, vol. 296, no. 1, pp. 216-223, 2001.

[87] D. Lee, K.-Y. Kim, Y. H. Noh et al., "Brimonidine blocks glutamate excitotoxicity-induced oxidative stress and preserves mitochondrial transcription factor a in ischemic retinal injury," PLoS ONE, vol. 7, no. 10, Article ID e47098, 2012.

[88] C.-J. Dong, Y. Guo, P. Agey, L. Wheeler, and W. A. Hare, " $\alpha 2$ adrenergic modulation of NMDA receptor function as a major mechanism of RGC protection in experimental glaucoma and retinal excitotoxicity," Investigative Ophthalmology \& Visual Science, vol. 49, no. 10, pp. 4515-4522, 2008.

[89] E. WoldeMussie, G. Ruiz, M. Wijono, and L. A. Wheeler, "Neuroprotection of retinal ganglion cells by brimonidine in rats with laser-induced chronic ocular hypertension," Investigative Ophthalmology \& Visual Science, vol. 42, no. 12, pp. 2849-2855, 2001.

[90] R. K. Lai, T. Chun, D. Hasson, S. Lee, F. Mehrbod, and L. Wheeler, "Alpha-2 adrenoceptor agonist protects retinal function after acute retinal ischemic injury in the rat," Visual Neuroscience, vol. 19, no. 2, pp. 175-185, 2002.

[91] H. Gao, X. Qiao, F. Hefti, J. G. Hollyfield, and B. Knusel, "Elevated mRNA expression of brain-derived neurotrophic factor in retinal ganglion cell layer after optic nerve injury," Investigative Ophthalmology \& Visual Science, vol. 38, no. 9, pp. 1840-1847, 1997.

[92] M. P. Lafuente, M. P. Villegas-Pérez, S. Mayor, M. E. Aguilera, J. Miralles de Imperial, and M. Vidal-Sanz, "Neuroprotective effects of brimonidine against transient ischemia-induced retinal ganglion cell death: A dose response in vivo study," Experimental Eye Research, vol. 74, no. 2, pp. 181-189, 2002.

[93] J. R. Ferencz, G. Gilady, O. Harel, M. Belkin, and E. I. Assia, "Topical brimonidine reduces collateral damage caused by laser photocoagulation for choroidal neovascularization," Graefe's Archive for Clinical and Experimental Ophthalmology, vol. 243, no. 9, pp. 877-880, 2005.

[94] D. W. Evans, S. L. Hosking, D. Gherghel, and J. D. Bartlett, "Contrast sensitivity improves after brimonidine therapy in primary open angle glaucoma: A case for neuroprotection," British Journal of Ophthalmology, vol. 87, no. 12, pp. 1463-1465, 2003.

[95] T. Krupin, J. M. Liebmann, D. S. Greenfield, R. Ritch, and S. Gardiner, "A randomized trial of brimonidine versus timolol in preserving visual function: results from the low-pressure glaucoma treatment study," American Journal of Ophthalmology, vol. 151, no. 4, pp. 671-681, 2011.

[96] P. Fagone and S. Jackowski, "Phosphatidylcholine and the CDPcholine cycle," Biochimica et Biophysica Acta (BBA) - Molecular and Cell Biology of Lipids, vol. 1831, no. 3, pp. 523-532, 2013.

[97] J. J. Secades, "Citicoline: pharmacological and clinical review, update," Revista de Neurologia (Spanish), vol. 63, no. S03, pp. S1-S73, 2016.

[98] G. Roberti, L. Tanga, M. Michelessi et al., "Cytidine 51diphosphocholine (Citicoline) in glaucoma: Rationale of its use, current evidence and future perspectives," International Journal of Molecular Sciences, vol. 16, no. 12, pp. 28401-28417, 2015.

[99] S. M. Wu and B. R. Maple, "Amino acid neurotransmitters in the retina: a functional overview," Vision Research, vol. 38, no. 10, pp. 1371-1384, 1998.
[100] V. Parisi, F. Oddone, L. Ziccardi, G. Roberti, G. Coppola, and G. Manni, "Citicoline and retinal ganglion cells: effects on morphology and function," Current Neuropharmacology, vol. 15, 2017.

[101] H. P. Chang, S. K. Yoon, S. N. Hae et al., "Neuroprotective effect of citicoline against KA-induced neurotoxicity in the rat retina," Experimental Eye Research, vol. 81, no. 3, pp. 350-358, 2005.

[102] F. Schuettauf, R. Rejdak, S. Thaler et al., "Citicoline and lithium rescue retinal ganglion cells following partial optic nerve crush in the rat," Experimental Eye Research, vol. 83, no. 5, pp. 11281134, 2006.

[103] V. Parisi, G. Coppola, L. Ziccardi, G. Gallinaro, and B. Falsini, "Cytidine-5/-diphosphocholine (Citicoline): A pilot study in patients with non-arteritic ischaemic optic neuropathy," European Journal of Neurology, vol. 15, no. 5, pp. 465-474, 2008.

[104] J. P. Giraldi, M. Virno, G. Covelli, G. Grechi, and F. De Gregorio, "Therapeutic value of citicoline in the treatment of glaucoma (computerized and automated perimetric investigation)," International Ophthalmology, vol. 13, no. 1-2, pp. 109-112, 1989.

[105] M. Virno, J. Pecori-Giraldi, A. Liguori, and F. De Gregorio, "The protective effect of citicoline on the progression of the perimetric defects in glaucomatous patients (perimetric study with a 10-year follow-up)," Acta Ophthalmologica Scandinavica, Supplement, vol. 78, no. 232, pp. 56-57, 2000.

[106] V. Parisi, G. Manni, G. Colacino, and M. G. Bucci, "Cytidine5 -diphosphocholine (citicoline) improves retinal and cortical responses in patients with glaucoma," Ophthalmology, vol. 106, no. 6, pp. 1126-1134, 1999.

[107] V. Parisi, "Electrophysiological assessment of glaucomatous visual dysfunction during treatment with cytidine-5/-diphosphocholine (citicoline): A study of 8 years of follow-up," Documenta Ophthalmologica, vol. 110, no. 1, pp. 91-102, 2005.

[108] L. Ottobelli, G. L. Manni, M. Centofanti, M. Iester, F. Allevena, and L. Rossetti, "Citicoline oral solution in glaucoma: Is there a role in slowing disease progression?" Ophthalmologica, vol. 229, no. 4, pp. 219-226, 2013.

[109] V. Parisi, M. Centofanti, L. Ziccardi et al., "Treatment with citicoline eye drops enhances retinal function and neural conduction along the visual pathways in open angle glaucoma," Graefe's Archive for Clinical and Experimental Ophthalmology, vol. 253, no. 8, pp. 1327-1340, 2015.

[110] S. R. Pandi-Perumal, V. Srinivasan, G. J. M. Maestroni, D. P. Cardinali, B. Poeggeler, and R. Hardeland, "Melatonin: nature's most versatile biological signal?” FEBS Journal, vol. 273, no. 13, pp. 2813-2838, 2006.

[111] G. Tosini, K. Baba, C. K. Hwang, and P. M. Iuvone, "Melatonin: an underappreciated player in retinal physiology and pathophysiology," Experimental Eye Research, vol. 103, pp. 8289, 2012.

[112] R. M. Slominski, R. J. Reiter, N. Schlabritz-Loutsevitch, R. S. Ostrom, and A. T. Slominski, "Melatonin membrane receptors in peripheral tissues: distribution and functions," Molecular and Cellular Endocrinology, vol. 351, no. 2, pp. 152-166, 2012.

[113] N. N. Osborne, "Serotonin and melatonin in the iris/ciliary processes and their involvement in intraocular pressure," Acta Neurobiol Exp (Wars), vol. 54, pp. 57-64, 1994.

[114] M. M. Macchi and J. N. Bruce, "Human pineal physiology and functional significance of melatonin," Frontiers in Neuroendocrinology, vol. 25, no. 3-4, pp. 177-195, 2004.

[115] D.-X. Tan, L. C. Manchester, E. Esteban-Zubero, Z. Zhou, and R. J. Reiter, "Melatonin as a potent and inducible endogenous 
antioxidant: synthesis and metabolism," Molecules, vol. 20, no. 10, pp. 18886-18906, 2015.

[116] I. Chowdhury, A. Sengupta, and S. K. Maitra, "Melatonin: Fifty years of scientific journey from the discovery in bovine pineal gland to delineation of functions in human," Indian Journal of Biochemistry and Biophysics, vol. 45, no. 5, pp. 289-304, 2008.

[117] P. Wongprayoon and P. Govitrapong, "Melatonin as a mitochondrial protector in neurodegenerative diseases," Cellular and Molecular Life Sciences, 2017.

[118] V. Srinivasan, D. P. Cardinali, U. S. Srinivasan et al., “Therapeutic potential of melatonin and its analogs in Parkinson's disease: focus on sleep and neuroprotection," Therapeutic Advances in Neurological Disorders, vol. 4, no. 5, pp. 297-317, 2011.

[119] F.-Q. Liang, L. Green, C. Wang, R. Alssadi, and B. F. Godley, "Melatonin protects human retinal pigment epithelial (RPE) cells against oxidative stress," Experimental Eye Research, vol. 78, no. 6, pp. 1069-1075, 2004.

[120] F. Q. Liang, T. S. Aleman, A. V. ZaixinYang, S. G. Cideciyan, S. G. Jacobson, and J. Bennett, "Melatonin delays photoreceptor degeneration in the rds/rds mouse," NeuroReport, vol. 12, no. 5, pp. 1011-1014, 2001.

[121] K. Baba, N. Pozdeyev, F. Mazzoni et al., "Melatonin modulates visual function and cell viability in the mouse retina via the MT1 melatonin receptor," Proceedings of the National Acadamy of Sciences of the United States of America, vol. 106, no. 35, pp. 15043-15048, 2009.

[122] S. Alcantara-Contreras, K. Baba, and G. Tosini, "Removal of melatonin receptor type 1 increases intraocular pressure and retinal ganglion cells death in the mouse," Neuroscience Letters, vol. 494, no. 1, pp. 61-64, 2011.

[123] M. C. Moreno, P. Sande, H. A. Marcos, N. De Zavalía, M. I. K. Sarmiento, and R. E. Rosenstein, "Effect of glaucoma on the retinal glutamate/glutamine cycle activity," The FASEB Journal, vol. 19, no. 9, pp. 1161-1162, 2005.

[124] D. A. Sáenz, A. P. Goldin, L. Minces, M. Chianelli, M. I. K. Sarmiento, and R. E. Rosenstein, "Effect of melatonin on the retinal glutamate/glutamine cycle in the golden hamster retina," The FASEB Journal, vol. 18, no. 15, pp. 1912-1913, 2004.

[125] A. Crooke, F. Huete-Toral, A. Martínez-Águila, A. Martín-Gil, and J. Pintor, "Melatonin and its analog 5-methoxycarbonylamino-N-acetyltryptamine potentiate adrenergic receptormediated ocular hypotensive effects in rabbits: Significance for combination therapy in glaucoma," The Journal of Pharmacology and Experimental Therapeutics, vol. 346, no. 1, pp. 138-145, 2013.

[126] J. B. Serle, R.-F. Wang, W. M. Peterson, R. Plourde, and B. R. Yerxa, "Effect of 5-MCA-NAT, a putative melatonin MT3 receptor agonist, on intraocular pressure in glaucomatous monkey eyes," Journal of Glaucoma, vol. 13, no. 5, pp. 385-388, 2004.

[127] N. Pescosolido, V. Gatto, A. Stefanucci, and D. Rusciano, "Oral treatment with the melatonin agonist agomelatine lowers the intraocular pressure of glaucoma patients," Ophthalmic and Physiological Optics, vol. 35, no. 2, pp. 201-205, 2015.

[128] M. C. Moreno, J. Campanelli, P. Sande, D. A. Sáenz, M. I. Keller Sarmiento, and R. E. Rosenstein, "Retinal oxidative stress induced by high intraocular pressure," Free Radical Biology \& Medicine, vol. 37, no. 6, pp. 803-812, 2004.

[129] M. L. Dubocovich, M. A. Rivera-Bermudez, M. J. Gerdin, and M. I. Masana, "Molecular pharmacology, regulation and function of mammalian melatonin receptors," Front Biosci, vol. 8, pp. d1093-d108, 2003.
[130] A. Carocci, A. Catalano, and M. S. Sinicropi, "Melatonergic drugs in development," Clinical Pharmacology \& Therapeutics, vol. 6, pp. 127-137, 2014.

[131] F. Huete-Toral, A. Crooke, A. Martínez-Águila, and J. Pintor, "Melatonin receptors trigger cAMP production and inhibit chloride movements in nonpigmented ciliary epithelial cells," The Journal of Pharmacology and Experimental Therapeutics, vol. 352, no. 1, article no. A23, pp. 119-128, 2015.

[132] J. Flammer, "The vascular concept of glaucoma," Survey of Ophthalmology, vol. 38, supplement, pp. S3-S6, 1994.

[133] N. N. Osborne, R. J. Casson, J. P. M. Wood, G. Chidlow, M. Graham, and J. Melena, "Retinal ischemia: mechanisms of damage and potential therapeutic strategies," Progress in Retinal and Eye Research, vol. 23, no. 1, pp. 91-147, 2004.

[134] V. P. Costa, A. Harris, E. Stefánsson et al., "The effects of antiglaucoma and systemic medications on ocular blood flow," Progress in Retinal and Eye Research, vol. 22, no. 6, pp. 769-805, 2003.

[135] C. Kaur, V. Sivakumar, R. Robinson, W. S. Foulds, C. D. Luu, and E.-A. Ling, "Neuroprotective effect of melatonin against hypoxia-induced retinal ganglion cell death in neonatal rats," Journal of Pineal Research, vol. 54, no. 2, pp. 190-206, 2013.

[136] J. Flammer, S. Orgül, V. P. Costa et al., "The impact of ocular blood flow in glaucoma," Progress in Retinal and Eye Research, vol. 21, no. 4, pp. 359-393, 2002.

[137] S. Arangino, A. Cagnacci, M. Angiolucci et al., "Effects of melatonin on vascular reactivity, catecholamine levels, and blood pressure in healthy men," American Journal of Cardiology, vol. 83, no. 9, pp. 1417-1419, 1999.

[138] S. Suzen, "Recent developments of melatonin related antioxidant compounds," Combinatorial Chemistry \& High Throughput Screening, vol. 9, no. 6, pp. 409-419, 2006.

[139] P. Gressens, L. Schwendimann, I. Husson et al., "Agomelatine, a melatonin receptor agonist with 5-HT2C receptor antagonist properties, protects the developing murine white matter against excitotoxicity," European Journal of Pharmacology, vol. 588, no. 1, pp. 58-63, 2008.

[140] A. Martínez-Águila, B. Fonseca, A. Bergua, and J. Pintor, "Melatonin analogue agomelatine reduces rabbit's intraocular pressure in normotensive and hypertensive conditions," European Journal of Pharmacology, vol. 701, no. 1-3, pp. 213-217, 2013.

[141] M. J. Millan, A. Gobert, F. Lejeune et al., "The novel melatonin agonist agomelatine (S20098) is an antagonist at 5hydroxytryptamine $2 \mathrm{C}$ receptors, blockade of which enhances the activity of frontocortical dopaminergic and adrenergic pathways," The Journal of Pharmacology and Experimental Therapeutics, vol. 306, no. 3, pp. 954-964, 2003.

[142] S. Conway, S. J. Canning, H. E. Howell et al., "Characterisation of human melatonin mt1 and MT2 receptors by CRE-luciferase reporter assay," European Journal of Pharmacology, vol. 390, no. 1-2, pp. 15-24, 2000.

[143] C. Álamo, F. López-Muñoz, and M. José Armada, “Agomelatina: un nuevo enfoque farmacológico en el tratamiento de la depresión con traducción clínica," Psiquiatría Biológica, vol. 15, no. 4, pp. 125-139, 2008.

[144] S.-W. Ying, B. Rusak, P. Delagrange, E. Mocaër, P. Renard, and B. Guardiola-Lemaître, "Melatonin analogues as agonists and antagonists in the circadian system and other brain areas," European Journal of Pharmacology, vol. 296, no. 1, pp. 33-42, 1996.

[145] G. Bonanno, R. Giambelli, L. Raiteri et al., "Chronic antidepressants reduce depolarization-evoked glutamate release and 
protein interactions favoring formation of SNARE complex in hippocampus," The Journal of Neuroscience, vol. 25, no. 13, pp. 3270-3279, 2005.

[146] S. Gupta, P. Singh, B. Sharma, and B. Sharma, "Neuroprotective effects of agomelatine and vinpocetine against chronic cerebral hypoperfusion induced vascular dementia," Current Neurovascular Research, vol. 12, no. 3, pp. 240-252, 2015.

[147] B. P. Jacobs and W. S. Browner, "Ginkgo biloba: A living fossil," American Journal of Medicine, vol. 108, no. 4, pp. 341-342, 2000.

[148] T. Wei, F.-F. Xiong, S.-D. Wang, K. Wang, Y.-Y. Zhang, and Q.H. Zhang, "Flavonoid ingredients of Ginkgo biloba leaf extract regulate lipid metabolism through Spl-mediated carnitine palmitoyltranferase 1A up-regulation," Journal of Biomedical Science, vol. 21, no. 1, article no. 87, 2014.

[149] J. Kobus-Cisowska, E. Flaczyk, M. Rudzińska, and D. Kmiecik, "Antioxidant properties of extracts from Ginkgo biloba leaves in meatballs," Meat Science, vol. 97, no. 2, pp. 174-180, 2014.

[150] I. Maitra, L. Marcocci, M. T. Droy-Lefaix, and L. Packer, "Peroxyl radical scavenging activity of Ginkgo biloba extract EGb 761," Biochemical Pharmacology, vol. 49, no. 11, pp. 16491655, 1995.

[151] H. Scholtyssek, W. Damerau, R. Wessel, and I. Schimke, "Antioxidative activity of ginkgolides against superoxide in an aprotic environment," Chemico-Biological Interactions, vol. 106, no. 3, pp. 183-190, 1997.

[152] R. Abdel-Kader, S. Hauptmann, U. Keil et al., "Stabilization of mitochondrial function by Ginkgo biloba extract (EGb 761)," Pharmacological Research, vol. 56, no. 6, pp. 493-502, 2007.

[153] A. Eckert, U. Keil, I. Scherping, S. Hauptmann, and W. E. Müller, "Stabilization of mitochondrial membrane potential and improvement of neuronal energy metabolism by Ginkgo biloba extract EGb 761," Annals of the New York Academy of Sciences, vol. 1056, pp. 474-485, 2005.

[154] K. K. Abu-Amero, J. Morales, and T. M. Bosley, "Mitochondrial abnormalities in patients with primary open-angle glaucoma," Investigative Ophthalmology \& Visual Science, vol. 47, no. 6, pp. 2533-2541, 2006.

[155] A. Eckert, U. Keil, S. Kressmann et al., "Effects of EGb 761 Ginkgo biloba extract on mitochondrial function and oxidative stress," Pharmacopsychiatry, vol. 36, 1, pp. S15-S23, 2003.

[156] M. Seif-El-Nasr and A. A. Abd El-Fattah, "Lipid peroxide, phospholipids, glutathione levels and superoxide dismutase activity in rat brain after ischaemia: Effect of ginkgo biloba extract," Pharmacological Research, vol. 32, no. 5, pp. 273-278, 1995.

[157] E. Dumont, E. Petit, T. Tarrade, and A. Nouvelot, "UV-C irradiation-induced peroxidative degradation of microsomal fatty acids and proteins: Protection by an extract of Ginkgo biloba (EGn 761)," Free Radical Biology \& Medicine, vol. 13, no. 3, pp. 197-203, 1992.

[158] E. Dumont, P. D’Arbigny, and A. Nouvelot, "Protection of polyunsaturated fatty acids against iron-dependent lipid peroxidation by a Ginkgo biloba extract (EGb 761)," Methods and Findings in Experimental and Clinical Pharmacology, vol. 17, no. 2, pp. 83-88, 1995.

[159] K. Kose and P. Dogan, "Lipoperoxidation induced by hydrogen peroxide in human erythrocyte membranes. 2. Comparison of the antioxidant effect of Ginkgo biloba extract (EGb 761) with those of water-soluble and lipid-soluble antioxidants," Journal of International Medical Research, vol. 23, no. 1, pp. 9-18, 1995.

[160] S. A. Barth, G. Iselmann, R. Engemann, and H. T. Heidemann, "Influences of Ginkgo biloba on cyclosporin a induced lipid peroxidation in human liver microsomes in comparison to vitamin E, glutathione and N-acetylcysteine," Biochemical Pharmacology, vol. 41, no. 10, pp. 1521-1526, 1991.

[161] M. T. Droy-Lefaix, "Effect of the antioxidant action of Ginkgo biloba extract (EGb 761) on aging and oxidative stress," Age (Omaha), vol. 20, no. 3, pp. 141-149, 1997.

[162] G. C. Chiou, "Review: effects of nitric oxide on eye diseases and their treatment," Journal of Ocular Pharmacology and Therapeutics, vol. 17, no. 2, pp. 189-198, 2001.

[163] J. S. Beckman and W. H. Koppenol, "Nitric oxide, superoxide, and peroxynitrite: the good, the bad, and the ugly," American Journal of Physiology-Cell Physiology, vol. 271, no. 5, pp. C1424C1437, 1996.

[164] A. W. Siu, S. W. Shan, K. K. Li et al., "Glutathione attenuates nitric oxide-induced retinal lipid and protein changes," Ophthalmic and Physiological Optics, vol. 35, no. 2, pp. 135-146, 2015.

[165] L. Marcocci, J. J. Maguire, M. T. Droy-Lefaix, and L. Packer, “The nitric oxide-scavenging properties of Ginkgo biloba extract EGb 761," Biochemical and Biophysical Research Communications, vol. 201, no. 2, pp. 748-755, 1994.

[166] H. Kobuchi, M. T. Droy-Lefaix, Y. Christen, and L. Packer, "Ginkgo biloba extract (EGb 761): Inhibitory effect on nitric oxide duction in the macrophage cell line RAW 264.7," Biochemical Pharmacology, vol. 53, no. 6, pp. 897-903, 1997.

[167] M.-T. Droy-Lefaix, B. Bonhomme, and M. Doly, "Protective effect of ginkgo biloba extract (EGB 761) on free radicalinduced changes in the electroretinogram of isolated rat retina," Drugs under Experimental and Clinical Research, vol. 17, no. 12, pp. 571-574, 1991.

[168] F. Sofi, L. Mannini, R. Marcucci et al., "Role of haemorheological factors in patients with retinal vein occlusion," Thrombosis and Haemostasis, vol. 98, no. 6, pp. 1215-1219, 2007.

[169] Y. Wu, S. Li, W. Cui, X. Zu, J. Du, and F. Wang, "Ginkgo biloba extract improves coronary blood flow in healthy elderly adults: Role of endothelium-dependent vasodilation," Phytomedicine, vol. 15, no. 3, pp. 164-169, 2008.

[170] H. S. Chung, A. Harris, J. K. Kristinsson, T. A. Ciulla, C. Kagemann, and R. Ritch, "Ginkgo biloba extract increases ocular blood flow velocity," Journal of Ocular Pharmacology and Therapeutics, vol. 15, no. 3, pp. 233-240, 1999.

[171] L. Quaranta, S. Bettelli, M. G. Uva, F. Semeraro, R. Turano, and E. Gandolfo, "Effect of Ginkgo biloba extract on preexisting visual field damage in normal tension glaucoma," Ophthalmology, vol. 110, no. 2, pp. 359-364, 2003.

[172] T. N. Malishevskaia and I. G. Dolgova, "Options for correction of endothelial dysfunction and oxidative stress in patients with primary open-angle glaucoma," Vestn Oftalmol, vol. 130, no. 5, pp. 72-73, 2014.

[173] J. Baleriola, J. Garcia-Feijoo, J. M. Martinez-de-la-Casa, A. Fernandez-Cruz, E. J. de la Rosa, and R. Fernandez-Durango, "Apoptosis in the trabecular meshwork of glaucomatous patients," Molecular Vision, vol. 14, pp. 1513-1516, 2008.

[174] R. W. Nickells, "Apoptosis of retinal ganglion cells in glaucoma: an update of the molecular pathways involved in cell death," Survey of Ophthalmology, vol. 43, supplement 1, pp. S151-S161, 1999.

[175] J. V. Smith, A. J. Burdick, P. Golik, I. Khan, D. Wallace, and Y. Luo, "Anti-apoptotic properties of Ginkgo biloba extract EGb 761 in differentiated PC12 cells," Cellular and Molecular Biology (Noisy-le-grand), vol. 48, no. 6, pp. 699-707, 2002. 
[176] J. Shen, W. Lee, Y. Gu, Y. Tong, P. C. W. Fung, and L. Tong, "Ginkgo biloba extract (EGb761) inhibits mitochondriadependent caspase pathway and prevents apoptosis in hypoxiareoxygenated cardiomyocytes," Chinese Medicine, vol. 6, article no. 8, 2011.

[177] Z.-G. Xie, X.-W. Wu, C.-R. Zhuang et al., "Protective effects of Ginkgo biloba extract on morphology and function of retinal ganglion cells after optic nerve transection in guinea pigs," Journal of Chinese Integrative Medicine, vol. 7, no. 10, pp. 940946, 2009.

[178] L. Ernster and G. Dallner, "Biochemical, physiological and medical aspects of ubiquinone function," BBA - Molecular Basis of Disease, vol. 1271, no. 1, pp. 195-204, 1995.

[179] R. Saini, “Coenzyme Q10: The essential nutrient," Journal of Pharmacy and Bioallied Sciences, vol. 3, no. 3, pp. 466-467, 2011.

[180] C. Schmelzer, I. Lindner, G. Rimbach, P. Niklowitz, T. Menke, and F. Döring, "Functions of coenzyme Q10 in inflammation and gene expression," BioFactors, vol. 32, no. 1-4, pp. 179-183, 2008.

[181] M. Spindler, M. F. Beal, and C. Henchcliffe, "Coenzyme Q10 effects in neurodegenerative disease," Neuropsychiatric Disease and Treatment, vol. 5, pp. 597-610, 2009.

[182] B. Uttara, A. V. Singh, P. Zamboni, and R. T. Mahajan, "Oxidative stress and neurodegenerative diseases: a review of upstream and downstream antioxidant therapeutic options," Current Neuropharmacology, vol. 7, no. 1, pp. 65-74, 2009.

[183] M. Somayajulu, S. McCarthy, M. Hung, M. Sikorska, H. Borowy-Borowski, and S. Pandey, "Role of mitochondria in neuronal cell death induced by oxidative stress; Neuroprotection by Coenzyme Q10," Neurobiology of Disease, vol. 18, no. 3, pp. 618-627, 2005.

[184] Y. H. Noh, K.-Y. Kim, M. S. Shim et al., "Inhibition of oxidative stress by coenzyme Q10 increases mitochondrial mass and improves bioenergetic function in optic nerve head astrocytes," Cell Death \& Disease, vol. 4, no. 10, article e820, 2013.

[185] R. J. Casson, "Possible role of excitotoxicity in the pathogenesis of glaucoma," Clinical \& Experimental Ophthalmology, vol. 34, no. 1, pp. 54-63, 2006.

[186] A. Atlante, P. Calissano, A. Bobba, S. Giannattasio, E. Marra, and S. Passarella, "Glutamate neurotoxicity, oxidative stress and mitochondria," FEBS Letters, vol. 497, no. 1, pp. 1-5, 2001.

[187] E. B. Dreyer, D. Zurakowski, R. A. Schumer, S. M. Podos, and S. A. Lipton, "Elevated glutamate levels in the vitreous body of humans and monkeys with glaucoma," JAMA Ophtalmology, vol. 114, no. 3, pp. 299-305, 1996.

[188] N. N. Osborne, G. Chidlow, M. S. Nash, and J. P. M. Wood, “The potential of neuroprotection in glaucoma treatment," Current Opinion in Ophthalmology, vol. 10, no. 2, pp. 82-92, 1999.

[189] Y. Nakajima, Y. Inokuchi, M. Nishi, M. Shimazawa, K. Otsubo, and H. Hara, "Coenzyme Q10 protects retinal cells against oxidative stress in vitro and in vivo," Brain Research, vol. 1226, pp. 226-233, 2008.

[190] C. Nucci, R. Tartaglione, A. Cerulli et al., "Retinal Damage Caused by High Intraocular Pressure-Induced Transient Ischemia is Prevented by Coenzyme Q10 in Rat," International Review of Neurobiology, vol. 82, pp. 397-406, 2007.

[191] R. Russo, F. Cavaliere, L. Rombolà et al., "Rational basis for the development of coenzyme Q10 as a neurotherapeutic agent for retinal protection," Progress in Brain Research, vol. 173, pp. 575$582,2008$.
[192] D. Lee, M. S. Shim, K.-Y. Kim et al., "Coenzyme Q10 inhibits glutamate excitotoxicity and oxidative stress-mediated mitochondrial alteration in a mouse model of glaucoma," Investigative Ophthalmology \& Visual Science, vol. 55, no. 2, pp. 993-1005, 2014.

[193] H. Levkovitch-Verbin, "Retinal ganglion cell apoptotic pathway in glaucoma: initiating and downstream mechanisms," Progress in Brain Research, vol. 220, pp. 37-57, 2015.

[194] S. Choudhury, Y. Liu, A. F. Clark, and I.-H. Pang, "Caspase-7: a critical mediator of optic nerve injury-induced retinal ganglion cell death," Molecular Neurodegeneration, vol. 10, article 40, 2015.

[195] R. Zalewska, B. Zalewski, J. Reszec, Z. Mariak, L. Zimnoch, and E. Proniewska-Skretek, "The expressions of Fas and caspase3 in human glaucomatous optic nerve axons," Medical Science Monitor, vol. 14, no. 12, pp. BR274-BR278, 2008.

[196] M. Lulli, E. Witort, L. Papucci et al., “oenzyme Q10 instilled as eye drops on the cornea reaches the retina and protects retinal layers from apoptosis in a mouse model of kainateinduced retinal damageCoQ10 eye drops protect retinal cells from apoptosis," Investigative Ophthalmology \& Visual Science, vol. 53, no. 13, pp. 8295-8302, 2012.

[197] V. Parisi, M. Centofanti, S. Gandolfi et al., "Effects of coenzyme Q10 in conjunction with vitamin e on retinal-evoked and cortical-evoked responses in patients with open-angle glaucoma," Journal of Glaucoma, vol. 23, no. 6, pp. 391-404, 2014.

[198] J. Niño, K. Tahvanainen, H. Uusitalo et al., "Cardiovascular effects of ophthalmic $0.5 \%$ timolol aqueous solution and $0.1 \%$ timolol hydrogel," Clinical Physiology and Functional Imaging, vol. 22, no. 4, pp. 271-278, 2002.

[199] N. Takahashi, T. Iwasaka, T. Sugiura et al., "Effect of coenzyme Q10 on hemodynamic response to ocular timolol," Journal of Cardiovascular Pharmacology, vol. 14, no. 3, pp. 462-468, 1989.

[200] C. H. Beckman, "Phenolic-storing cells: Keys to programmed cell death and periderm formation in wilt disease resistance and in general defence responses in plants?" Physiological and Molecular Plant Pathology, vol. 57, no. 3, pp. 101-110, 2000.

[201] K. B. Pandey and S. I. Rizvi, "Plant polyphenols as dietary antioxidants in human health and disease," Oxidative Medicine and Cellular Longevity, vol. 2, no. 5, pp. 270-278, 2009.

[202] A. Silvia, M. Y. Avramovich-Tirosh, L. Reznichenko et al., "Multifunctional activities of green tea catechins in neuroprotection: modulation of cell survival genes, iron-dependent oxidative stress and PKC signaling pathway," Neurosignals, vol. 14, no. 1-2, pp. 46-60, 2005.

[203] O. Weinreb, S. Mandel, and M. B. H. Youdim, "Gene and protein expression profiles of anti- and pro-apoptotic actions of dopamine, R-apomorphine, green tea polyphenol (-)epigallocatechine-3-gallate, and melatonin," Annals of the New York Academy of Sciences, vol. 993, pp. 351-393, 2003.

[204] K. Ishige, D. Schubert, and Y. Sagara, "Flavonoids protect neuronal cells from oxidative stress by three distinct mechanisms," Free Radical Biology \& Medicine, vol. 30, no. 4, pp. 433-446, 2001.

[205] H. Schroeter, C. Boyd, J. P. E. Spencer, R. J. Williams, E. Cadenas, and C. Rice-Evans, "MAPK signaling in neurodegeneration: Influences of flavonoids and of nitric oxide," Neurobiology of Aging, vol. 23, no. 5, pp. 861-880, 2002.

[206] J. H. Chung, J. H. Han, E. J. Hwang et al., "Dual mechanisms of green tea extract (EGCG)-induced cell survival in human epidermal keratinocytes," Federation of American Societies for 
Experimental Biology (FASEB) Journal, vol. 17, no. 13, pp. 19131915, 2003.

[207] C. Chen, R. Yu, E. D. Owuor, and A.-N. Tony Kong, "Activation of antioxidant-response element (ARE), mitogen-activated protein kinases (MAPKs) and caspases by major green tea polyphenol components during cell survival and death," Archives of Pharmacal Research, vol. 23, no. 6, pp. 605-612, 2000.

[208] M. Lorenz, S. Wessler, E. Follmann et al., "A constituent of green tea, epigallocatechin-3-gallate, activates endothelial nitric oxide synthase by a phosphatidylinositol-3-OH-kinase-, cAMP-dependent protein kinase-, and Akt-dependent pathway and leads to endothelial-dependent vasorelaxation," The Journal of Biological Chemistry, vol. 279, no. 7, pp. 6190-6195, 2004.

[209] Y. Levites, T. Amit, S. Mandel, and M. B. H. Youdim, "NeuropNeuroprotection and neurorescue against Abeta toxicity and PKC-dependent release of nonamyloidogenic soluble precursor protein by green tea polyphenol (-)-epigallocatechin3-gallate," Federation of American Societies for Experimental Biology (FASEB) Journal, vol. 17, no. 8, pp. 952-954, 2003.

[210] K. Ono, Y. Yoshiike, A. Takashima, K. Hasegawa, H. Naiki, and M. Yamada, "Potent anti-amyloidogenic and fibril-destabilizing effects of polyphenols in vitro: implications for the prevention and therapeutics of Alzheimer's disease," Journal of Neurochemistry, vol. 87, no. 1, pp. 172-181, 2003.

[211] B. Zhang, R. Safa, D. Rusciano, and N. N. Osborne, "Epigallocatechin gallate, an active ingredient from green tea, attenuates damaging influences to the retina caused by ischemia/reperfusion," Brain Research, vol. 1159, no. 1, pp. 40-53, 2007.

[212] C. Shen, L. Chen, L. Jiang, and T. Y. Y. Lai, "Neuroprotective effect of epigallocatechin-3-gallate in a mouse model of chronic glaucoma," Neuroscience Letters, vol. 600, pp. 132-136, 2015.

[213] J. Xie, L. Jiang, T. Zhang, Y. Jin, D. Yang, and F. Chen, "Neuroprotective effects of Epigallocatechin-3-gallate (EGCG) in optic nerve crush model in rats," Neuroscience Letters, vol. 479, no. 1, pp. 26-30, 2010.

[214] N. N. Osborne and J. P. M. Wood, "Metipranolol blunts nitric oxide-induced lipid peroxidation and death of retinal photoreceptors: a comparison with other anti-glaucoma drugs," Investigative Ophthalmology \& Visual Science, vol. 45, no. 10, pp. 3787-3795, 2004.

[215] W. Ju, I. Chung, K. Kim et al., "Sodium nitroprusside selectively induces apoptotic cell death in the outer retina of the rat," NeuroReport, vol. 12, no. 18, pp. 4075-4079, 2001.

[216] B. Zhang and N. N. Osborne, "Oxidative-induced retinal degeneration is attenuated by epigallocatechin gallate," Brain Research, vol. 1124, no. 1, pp. 176-187, 2006.

[217] M. Suganuma, S. Okabe, M. Oniyama, Y. Tada, H. Ito, and H. Fujiki, "Wide distribution of $[3 \mathrm{H}](-)$-epigallocatechin gallate, a cancer preventive tea polyphenol, in mouse tissue," Carcinogenesis, vol. 19, no. 10, pp. 1771-1776, 1998.

[218] R. A. Isbrucker, J. Bausch, J. A. Edwards, and E. Wolz, "Safety studies on epigallocatechin gallate (EGCG) preparations. Part 1: Genotoxicity," Food and Chemical Toxicology, vol. 44, no. 5, pp. 626-635, 2006

[219] B. Falsini, D. Marangoni, T. Salgarello et al., "Effect of epigallocatechin-gallate on inner retinal function in ocular hypertension and glaucoma: A short-term study by pattern electroretinogram," Graefe's Archive for Clinical and Experimental Ophthalmology, vol. 247, no. 9, pp. 1223-1233, 2009.

[220] B. B. Aggarwal, A. Bhardwaj, R. S. Aggarwal, N. P. Seeram, S. Shishodia, and Y. Takada, "Role of resveratrol in prevention and therapy of cancer: preclinical and clinical studies," Anticancer Reseach, vol. 24, no. 5A, pp. 2783-2840, 2004.

[221] S. Bradamante, L. Barenghi, and A. Villa, "Cardiovascular protective effects of resveratrol," Cardiovascular Drug Reviews, vol. 22, no. 3, pp. 169-188, 2004.

[222] H. Wang, Y.-J. Yang, H.-Y. Qian, Q. Zhang, H. Xu, and J.-J. $\mathrm{Li}$, "Resveratrol in cardiovascular disease: what is known from current research?" Heart Failure Reviews, vol. 17, no. 3, pp. 437448, 2012.

[223] J. A. Baur and D. A. Sinclair, "Therapeutic potential of resveratrol: the in vivo evidence," Nature Reviews Drug Discovery, vol. 5, no. 6, pp. 493-506, 2006.

[224] V. Cucciolla, A. Borriello, A. Oliva, P. Galletti, V. Zappia, and F. D. Ragione, "Resveratrol: from basic science to the clinic," Cell Cycle, vol. 6, no. 20, pp. 2495-2510, 2007.

[225] A. L. Holme and S. Pervaiz, "Resveratrol in cell fate decisions," Journal of Bioenergetics and Biomembranes, vol. 39, no. 1, pp. 5963, 2007.

[226] M. Kodali, V. K. Parihar, B. Hattiangady, V. Mishra, B. Shuai, and A. K. Shetty, "Resveratrol prevents age-related memory and mood dysfunction with increased hippocampal neurogenesis and microvasculature, and reduced glial activation," Scientific Reports, vol. 5, article 8075, 2015.

[227] S. S. Karuppagounder, J. T. Pinto, H. Xu, H.-L. Chen, M. F. Beal, and G. E. Gibson, "Dietary supplementation with resveratrol reduces plaque pathology in a transgenic model of Alzheimer's disease," Neurochemistry International, vol. 54, no. 2, pp. 111-118, 2009.

[228] H. Capiralla, V. Vingtdeux, H. Zhao et al., "Resveratrol mitigates lipopolysaccharide- and $\mathrm{A} \beta$-mediated microglial inflammation by inhibiting the TLR4/NF- $\kappa$ B/STAT signaling cascade," Journal of Neurochemistry, vol. 120, no. 3, pp. 461-472, 2012.

[229] D. Albani, L. Polito, S. Batelli et al., "The SIRT1 activator resveratrol protects SK-N-BE cells from oxidative stress and against toxicity caused by $\alpha$-synuclein or amyloid- $\beta$ (1-42) peptide," Journal of Neurochemistry, vol. 110, no. 5, pp. 14451456, 2009.

[230] A. Kumar, P. S. Naidu, N. Seghal, and S. S. V. Padi, "Neuroprotective effects of resveratrol against intracerebroventricular colchicine-induced cognitive impairment and oxidative stress in rats," Pharmacology, vol. 79, no. 1, pp. 17-26, 2007.

[231] C. Luna, G. Li, P. B. Liton et al., "Resveratrol prevents the expression of glaucoma markers induced by chronic oxidative stress in trabecular meshwork cells," Food and Chemical Toxicology, vol. 47, no. 1, pp. 198-204, 2009.

[232] D. Pirhan, N. Yüksel, E. Emre, A. Cengiz, and D. Kürşat Yildiz, "Riluzole- and resveratrol-induced delay of retinal ganglion cell death in an experimental model of glaucoma," Current Eye Research, vol. 41, no. 1, pp. 59-69, 2016.

[233] J. D. Lindsey, K. X. Duong-Polk, D. Hammond, C. K.-S. Leung, and R. N. Weinreb, "Protection of injured retinal ganglion cell dendrites and unfolded protein response resolution after longterm dietary resveratrol," Neurobiology of Aging, vol. 36, no. 5, pp. 1969-1981, 2015.

[234] N. Razali, R. Agarwal, P. Agarwal et al., "Role of adenosine receptors in resveratrol-induced intraocular pressure lowering in rats with steroid-induced ocular hypertension," Clinical \& Experimental Ophthalmology, vol. 43, no. 1, pp. 54-66, 2015.

[235] M. Y. Avila, R. A. Stone, and M. M. Civan, "A 1-, A 2a- and A 3subtype adenosine receptors modulate intraocular pressure in the mouse," British Journal of Pharmacology, vol. 134, no. 2, pp. 241-245, 2001. 
[236] X. Q. Liu, B. J. Wu, W. H. Pan et al., "Resveratrol mitigates rat retinal ischemic injury: the roles of matrix metalloproteinase-9, inducible nitric oxide, and heme oxygenase-1," Journal of Ocular Pharmacology and Therapeutics, vol. 29, no. 1, pp. 33-40, 2013.

[237] H. Hosseinzadeh and M. Nassiri-Asl, "Review of the protective effects of rutin on the metabolic function as an important dietary flavonoid," Journal of Endocrinological Investigation, vol. 37, no. 9, pp. 783-788, 2014.

[238] H. Kim, H. Kong, B. Choi et al., "Metabolic and pharmacological properties of rutin, a dietary quercetin glycoside, for treatment of inflammatory bowel disease," Pharmaceutical Research, vol. 22, no. 9, pp. 1499-1509, 2005.

[239] A. Ganeshpurkar and A. K. Saluja, "The Pharmacological Potential of Rutin," Saudi Pharmaceutical Journal, vol. 25, no. 2, pp. 149-164, 2017.

[240] N. Pescosolido and A. Librando, "Oral administration of an association of forskolin, rutin and vitamins $\mathrm{B} 1$ and $\mathrm{B} 2$ potentiates the hypotonising effects of pharmacological treatments in POAG patients," La Clinica Terapeutica, vol. 161, no. 3, pp. e81e85, 2010.

[241] M. Nebbioso, G. Belcaro, A. Librando, D. Rusciano, R. D. Steigerwalt Jr., and N. Pescosolido, "Forskolin and rutin prevent intraocular pressure spikes after Nd:YAG laser iridotomy," Panminerva Medica, vol. 54, suppl 4, no. 1, pp. 77-82, 2012.

[242] M. Nebbioso, D. Rusciano, B. Pucci, A. M. Zicari, R. Grenga, and N. Pescocolido, "Treatment of glaucomatous patients by means of food supplement to reduce the ocular discomfort: A double blind randomized trial," European Review for Medical and Pharmacological Sciences, vol. 17, no. 8, pp. 1117-1122, 2013.

[243] L. Machawal and A. Kumar, "Possible involvement of nitric oxide mechanism in the neuroprotective effect of rutin against immobilization stress induced anxiety like behaviour, oxidative damage in mice," Pharmacological Reports, vol. 66, no. 1, pp. 1521, 2014

[244] K. B. Magalingam, A. Radhakrishnan, and N. Haleagrahara, "Rutin, a bioflavonoid antioxidant protects rat pheochromocytoma (PC-12) cells against 6-hydroxydopamine (6-OHDA)induced neurotoxicity," International Journal of Molecular Medicine, vol. 32, no. 1, pp. 235-240, 2013.

[245] J.-Y. Na, S. Kim, K. Song, and J. Kwon, "Rutin Alleviates Prion Peptide-Induced Cell Death Through Inhibiting Apoptotic Pathway Activation in Dopaminergic Neuronal Cells," Cellular and Molecular Neurobiology, vol. 34, no. 7, pp. 1071-1079, 2014.

[246] K. B. Magalingam, A. Radhakrishnan, P. Ramdas, and N. Haleagrahara, "Quercetin glycosides induced neuroprotection by changes in the gene expression in a cellular model of Parkinson's disease," Journal of Molecular Neuroscience, vol. 55, no. 3, pp. 609-617, 2015.

[247] M. Nakayama, M. Aihara, Y.-N. Chen, M. Araie, K. TomitaYokotani, and T. Iwashina, "Neuroprotective effects of flavonoids on hypoxia-, glutamate-, and oxidative stress-induced retinal ganglion cell death," Molecular Vision, vol. 17, pp. 1784-1793, 2011.

[248] M. S. Ola, M. M. Ahmed, R. Ahmad, H. M. Abuohashish, S. S. Al-Rejaie, and A. S. Alhomida, "Neuroprotective effects of rutin in streptozotocin-induced diabetic rat retina," Journal of Molecular Neuroscience, vol. 56, no. 2, pp. 440-448, 2015.

[249] C. Cunha, R. Brambilla, and K. L. Thomas, "A simple role for BDNF in learning and memory?" Frontiers in Molecular Neuroscience, vol. 3, article 1, 2010.

[250] J. Lu, D.-M. Wu, B. Hu, Y.-L. Zheng, Z.-F. Zhang, and Y.-J. Wang, "NGF-dependent activation of Trka pathway: A mechanism for the neuroprotective effect of troxerutin in d-galactose-treated mice," Brain Pathology, vol. 20, no. 5, pp. 952-965, 2010.

[251] M. S. Shim, K.-Y. Kim, and W.-K. Ju, "Role of cyclic AMP in the eye with glaucoma," BMB Reports, vol. 50, no. 2, pp. 60-70, 2017.

[252] R. G. Corredor, E. F. Trakhtenberg, W. Pita-Thomas, X. Jin, Y. Hu, and J. L. Goldberg, "Soluble adenylyl cyclase activity is necessary for retinal ganglion cell survival and axon growth," The Journal of Neuroscience, vol. 32, no. 22, pp. 7734-7744, 2012. 

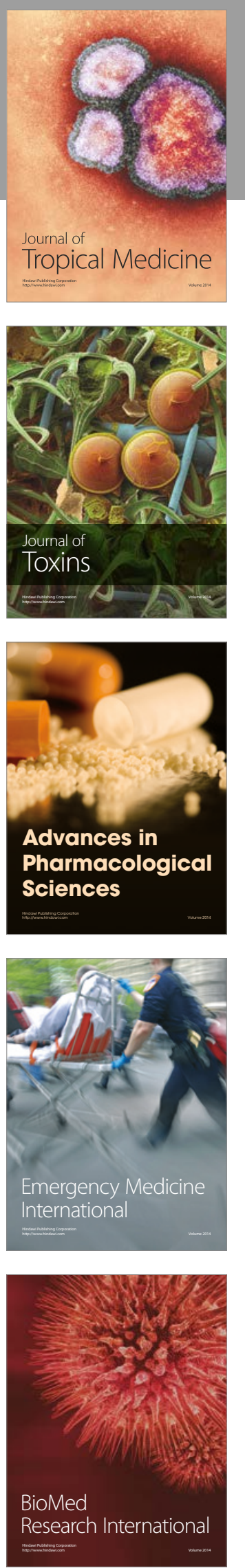
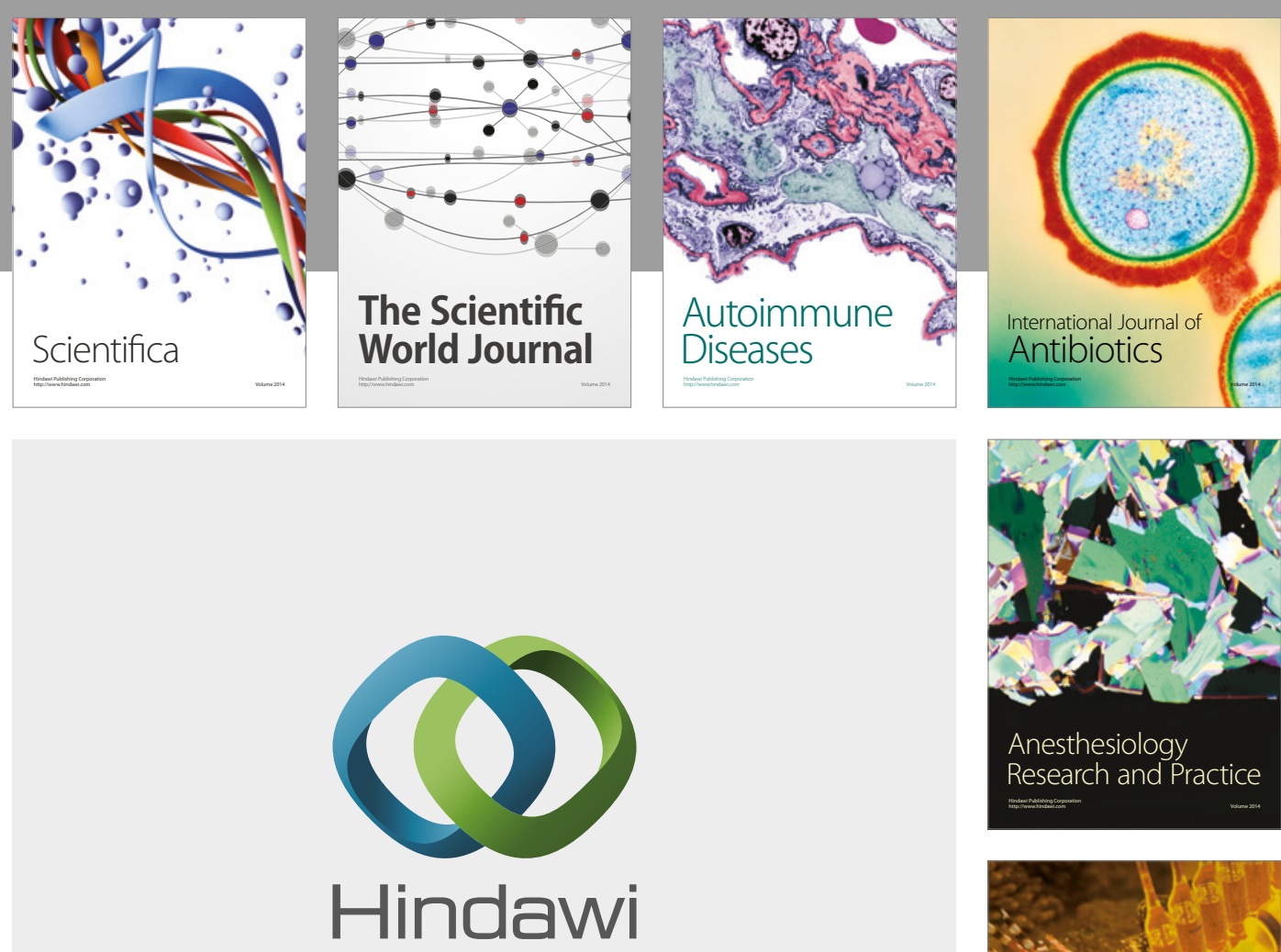

Submit your manuscripts at

https://www.hindawi.com
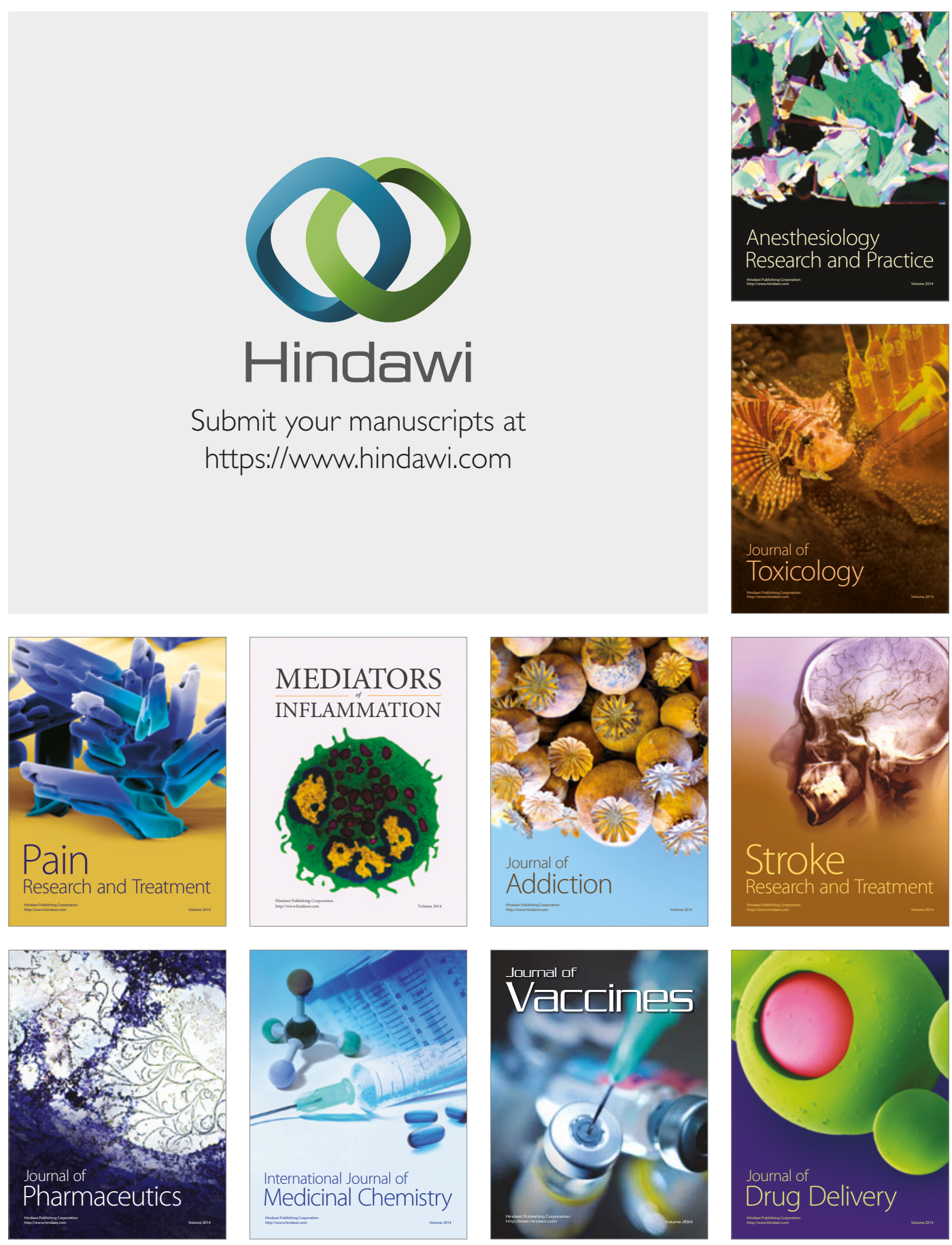